\title{
A simulation analysis of the advective effect on evaporation using a two-phase heat and mass flow model
}

\author{
Yijian Zeng, ${ }^{1,2}$ Zhongbo $\mathrm{Su}^{2}{ }^{2} \mathrm{Li}$ Wan, ${ }^{1}$ and Jun $\mathrm{Wen}^{3}$ \\ Received 25 March 2011; revised 12 September 2011; accepted 17 September 2011; published 27 October 2011.
}

[1] The concept of enhanced vapor transfer in unsaturated soils has been questioned for its reliance on soil temperature gradient, which leads to consideration of other mechanisms of vapor transfer, e.g., advective vapor transfer due to soil air pressure gradient. Although the advective flux is an important portion of evaporation, there is a lack of knowledge of its effect on evaporation. In order to assess the dependence of evaporation on the soil air pressure gradient, a vertical one-dimensional two-phase heat and mass flow model is developed that fully considers diffusion, advection, and dispersion. The proposed model is calibrated with field measurements of soil moisture content and temperature in the Badain Jaran Desert. The proposed model is then used to investigate the advective effect in both low- and high-permeability soils. The advective effect is reflected by underestimating evaporation when the airflow is neglected and is more evident in the low-permeability soil. Neglecting airflow causes an underestimation error of $53.3 \%$ on the day right after a rainfall event in the low-permeability soil $\left(7.9 \times 10^{-4} \mathrm{~cm} \mathrm{~s}^{-1}\right)$ and $33.3 \%$ in the high-permeability soil $\left(2 \times 10^{-3} \mathrm{~cm} \mathrm{~s}^{-1}\right)$. The comparisons of driving forces and conductivities show that the isothermal liquid flux, driven by the soil matric potential gradient, is the main reason for the underestimation error.

Citation: Zeng, Y., Z. Su, L. Wan, and J. Wen (2011), A simulation analysis of the advective effect on evaporation using a two-phase heat and mass flow model, Water Resour. Res., 47, W10529, doi:10.1029/2011WR010701.

\section{Introduction}

[2] Evaporation from unsaturated soil is a continually discussed issue that involves physical processes, including phase change, vapor transport, liquid flow, and heat transfer. Assuming the evaporative demand is constant, the soil drying process in the absence of a water table has been conceptualized as three stages: a constant-rate stage, a falling-rate stage, and a slow-rate stage [Hillel, 2004]. In correspondence to the three different evaporation stages, the vertical distribution of soil moisture can be described to be a three-layer model. Each stage of evaporation connects to one of the three soil layers covering the surface [Kobayashi et al., 1998]. In the first stage, an excess of liquid in soil pores (wet soil layer, WSL) covers the surface. In the second stage, liquid and vapor simultaneously transport, and a phase transformation zone (PTZ) forms on the top of the WSL. In the final stage, the dry surface layer (DSL) forms over the PTZ where only vapor phase flow is allowed. Prat [2002] labeled the same three soil layers as the dry zone, two-phase zone, and liquid zone, while Yiotis et al. [2004,

\footnotetext{
${ }^{1}$ School of Water Resources and Environment, China University of Geosciences, Beijing, China.

${ }^{2}$ Faculty of Geo-Information Science and Earth Observation, University of Twente, Enschede, Netherlands.

${ }^{3}$ Key Laboratory of Land Surface Process and Climate Change in Cold and Arid Region, Cold and Arid Regions Environmental and Engineering Research Institute, Chinese Academy of Sciences, Lanzhou, China.
}

Copyright 2011 by the American Geophysical Union. 0043-1397/11/2011WR010701
2005] call them the dry/gas region, film region, and liquid region. Among these studies, no large difference exists in distinguishing different soil layers associated with different evaporation stages, except for PTZ. The concurrent vapor and liquid flux in PTZ was originally described by Philip and de Vries [1957] (hereafter PdV model) as the evaporationcondensation through a series of liquid islands. On the basis of this description, an enhancement factor for vapor transfer was put forward considering the microscopic thermal gradient in air-filled pores [Philip and de Vries, 1957].

[3] The enhanced vapor transfer has been questioned for more than a decade since Webb and Ho's [1998] comprehensive review. The root of the doubt centers on the lack of direct measurement evidence [Shokri et al., 2009]. The enhancement factor in the PdV model is only valid when a temperature gradient exists. If there is no temperature gradient, there is no enhancement. However, Webb and Ho [1998] pointed out that vapor diffusion was enhanced even there was no temperature gradient, implying that an additional mechanism should be included in the PdV model. Before Webb and Ho's review, Rose [1968a, 1968b] claimed that the enhanced vapor transfer was perhaps partially caused by the advective mass flow of air through the soil. Following this idea, the advective flux induced by diurnal heating and cooling of the soil surface was proposed to be the omitted mechanism in the PdV model by Cahill and Parlange [1998] and Parlange et al. [1998] (hereafter CP model). Notwithstanding a close match between the CP model and the field observation, the enhanced vapor flow due to factors other than the temperature effect was still not taken into account. Actually, the vapor can be transferred 
as part of the bulk flow of dry air that is purely driven by the air pressure gradient in the soil [Olivella and Gens, 2000]. There is a need to study the air pressure gradientinduced vapor transfer (advective vapor transfer) using a two-phase flow model that treats dry air as a gas phase and soil water as a liquid phase.

[4] The thermal effect on evaporation from unsaturated soil has been studied by many researchers [Bittelli et al., 2008; Milly 1984a, 1984b; Saito et al., 2006; Sakai et al., 2009]. Most investigators employed the phenomenological scheme developed by Philip and de Vries [1957]. Nevertheless, the neglect of airflow in the PdV model restrains the analysis of the advective effect on evaporation. A two-phase heat and mass flow model can be used to investigate the vapor transport induced by airflow and has been applied in many engineering fields, such as geothermal engineering [Thomas et al., 1998; Thomas and Sansom, 1995], drying engineering [Kowalski, 2008], and environmental engineering [Pruess, 2004; Schrefler, 2004]. However, no particular attention has been paid to examining the advective effect on evaporation.

[5] This paper aims to investigate the advective effect on evaporation by using a proposed two-phase mass and heat flow model. In section 2, the proposed model is developed on the basis of the revised PdV model [Milly, 1982]. According to the field measurement of soil moisture content and temperature, the model is calibrated. In section 3, the advective effect on the evaporation is examined by analyzing driving forces and conductivities. Discussion and conclusions are presented in section 4.

\section{Model Description and Inputs}

\subsection{Two-Phase Model}

\subsubsection{Moisture Equation}

[6] Soil water is present in a liquid and a gaseous phase, and following Milly [1982], the total moisture balance is expressed as

$$
\frac{\partial}{\partial t}\left(\rho_{L} \theta+\rho_{V} \theta_{a}\right)=-\frac{\partial}{\partial z}\left(q_{L}+q_{V}\right),
$$

where $\rho_{L}\left(\mathrm{~kg} \mathrm{~m}^{-3}\right)$ represents the density of liquid water, $\rho_{V}\left(\mathrm{~kg} \mathrm{~m}^{-3}\right)$ is the density of water vapor, $\theta\left(\mathrm{m}^{3} \mathrm{~m}^{-3}\right)$ is the volumetric water content, $z(\mathrm{~m})$ is the vertical space coordinate, positive upward, $\theta_{a}\left(\mathrm{~m}^{3} \mathrm{~m}^{-3}\right)$ is the volumetric air content, $q_{L}\left(\mathrm{~kg} \mathrm{~m}^{-2} \mathrm{~s}^{-1}\right)$ is the liquid flux, and $q_{V}$ $\left(\mathrm{kg} \mathrm{m}^{-2} \mathrm{~s}^{-1}\right)$ is the vapor flux. The liquid flux is expressed by a generalized form of Darcy's law:

$$
q_{L}=-\rho_{L} K \frac{\partial\left(\frac{h_{w}}{\gamma_{w}}+z\right)}{\partial z},
$$

where $h_{w}(\mathrm{~Pa})$ is the pore water pressure, $\gamma_{w}\left(\mathrm{~kg} \mathrm{~m}^{-2} \mathrm{~s}^{-2}\right)$ is the specific weight of water, and $K\left(\mathrm{~m} \mathrm{~s}^{-1}\right)$ is the hydraulic conductivity. According to Groenevelt and Kay [1974], the effect of the heat of wetting on the pressure field and the resulting flow are taken into account by Milly [1982], which leads to an additional liquid flow term in equation (2), so that

$$
q_{L}=-\rho_{L} K \frac{\partial\left(\frac{h_{w}}{\gamma_{w}}+z\right)}{\partial z}-\rho_{L} D_{T D} \frac{\partial T}{\partial z},
$$

where $D_{T D}\left(\mathrm{~m}^{2} \mathrm{~s}^{-1}{ }^{\circ} \mathrm{C}^{-1}\right)$ is the transport coefficient for adsorbed liquid flow due to the temperature gradient and $T\left({ }^{\circ} \mathrm{C}\right)$ is the temperature. According to the definition of capillary potential, $h$ could be expressed as the difference between the pore air pressure and the pore water pressure [Gray and Hassanizadeh, 1991; Fredlund and Rahardjo, 1993; Thomas and Sansom, 1995]:

$$
h=\frac{h_{w}-P_{g}}{\gamma_{w}}
$$

where $h(\mathrm{~m})$ is the capillary pressure head and $P_{g}(\mathrm{~Pa})$ is the pore air pressure. Substituting equation (4) into (3) yields

$$
q_{L}=-\rho_{L} K \frac{\partial}{\partial z}\left(h+\frac{p_{g}}{\gamma_{w}}+z\right)-\rho_{L} D_{T D} \frac{\partial T}{\partial z} .
$$

Considering the temperature dependence of hydraulic conductivity, equation (5) can be rewritten as [Philip and de Vries, 1957]

$$
q_{L}=-\rho_{L}[\underbrace{K_{L h} \frac{\partial}{\partial z}\left(h+\frac{P_{g}}{\gamma_{w}}\right)}_{\substack{\text { Liquid Flux } \\
q_{L h}+q_{L a}}}+\underbrace{\left(K_{L T}+D_{T D}\right) \frac{\partial T}{\partial z}}_{\begin{array}{c}
\text { Thermal Liquid Flux } \\
q_{L T}
\end{array}}+K_{L h}]
$$

where $q_{L h}\left(\mathrm{~kg} \mathrm{~m}^{-2} \mathrm{~s}^{-1}\right)$ is the isothermal liquid flux, $q_{L T}$ $\left(\mathrm{kg} \mathrm{m}^{-2} \mathrm{~s}^{-1}\right)$ is the thermal liquid flux, $q_{L a}\left(\mathrm{~kg} \mathrm{~m}^{-2} \mathrm{~s}^{-1}\right)$ $\left(=\rho_{L}\left(K_{L h} / \gamma_{w}\right)\left(\partial P_{g} / \partial z\right)=K_{L a}\left(\partial P_{g} / \partial z\right)\right)$ is the advective liquid flux due to air pressure gradient, $K_{L a}(\mathrm{~s})$ is the advective liquid transport coefficient, $K_{L h}\left(\mathrm{~m} \mathrm{~s}^{-1}\right)$ is the isothermal hydraulic conductivity, and $K_{L T}\left(\mathrm{~m}^{2} \mathrm{~s}^{-1}{ }^{\circ} \mathrm{C}^{-1}\right)$ is the thermal hydraulic conductivity.

[7] The vapor flux is expressed by a generalized form of Fick's law:

$$
q_{V}=-D_{e} \frac{\partial \rho_{V}}{\partial z}
$$

where $D_{e}\left(\mathrm{~m}^{2} \mathrm{~s}^{-1}\right)$ is the molecular diffusivity of water vapor in soil. When the dry air is considered, the vapor flow is assumed to be induced in three ways: first, the diffusive transfer, driven by a vapor pressure gradient (equation (7)); second, the advective transfer, as part of the bulk flow of air $\left(\rho_{V}\left(q_{a a} / \rho_{d a}\right)\right)$; and, third, the dispersive transfer due to longitudinal dispersivity $\left(-D_{V g}\left(\partial \rho_{V} / \partial z\right)\right)$. Accordingly, equation (7) can be rewritten as

$$
q_{V}=-[\underbrace{D_{e} \frac{\partial \rho_{V}}{\partial z}}_{\text {Diffusion }}-\underbrace{\rho_{V} \frac{q_{a a}}{\rho_{d a}}}_{\text {Advection }}+\underbrace{D_{V g} \frac{\partial \rho_{V}}{\partial z}}_{\text {Dispersion }}],
$$

where $q_{a a}\left(\mathrm{~kg} \mathrm{~m}^{-2} \mathrm{~s}^{-1}\right)$ is the advective dry air flux $\left(q_{a a}=-\rho_{d a}\left(S_{a} k_{g} / \mu_{a}\right)\left(\partial P_{g} / \partial z\right)\right), \rho_{d a}\left(\mathrm{~kg} \mathrm{~m}^{-3}\right)$ is the dry air density, $D_{V g}\left(\mathrm{~m}^{2} \mathrm{~s}^{-1}\right)$ is the gas phase longitudinal dispersion coefficient, $S_{a}\left(=1-S_{r}\right)$ is the degree of air saturation of the soil, $S_{r}(=\theta / \varepsilon)$ is the degree of saturation of soil, $\varepsilon$ is the porosity, $k_{g}\left(\mathrm{~m}^{2}\right)$ is the intrinsic air permeability, and $\mu_{a}\left(1.846 \times 10^{-5} \mathrm{~kg} \mathrm{~m}^{-1} \mathrm{~s}^{-1}\right)$ is the air viscosity. 
[8] Considering that vapor density is a function of matric potential and temperature, the vapor flux can be divided into isothermal and thermal components. According to the chain rule for partial derivatives, the vapor flux in equation (8) could be rewritten with three state variables as

$$
\begin{aligned}
q_{V} & =q_{V h}+q_{V T}+q_{V a} \\
& =-\left[\left(D_{e}+D_{V g}\right) \frac{\partial \rho_{V}}{\partial h} \frac{\partial h}{\partial z}+\left(D_{e}+D_{V g}\right) \frac{\partial \rho_{V}}{\partial T} \frac{\partial T}{\partial z}+\rho_{V} \frac{S_{a} k_{g}}{\mu_{a}} \frac{\partial P_{g}}{\partial z}\right],
\end{aligned}
$$

where $q_{V h}\left(\mathrm{~kg} \mathrm{~m}^{-2} \mathrm{~s}^{-1}\right)$ is the isothermal vapor flux, $q_{V T}$ $\left(\mathrm{kg} \mathrm{m}^{-2} \mathrm{~s}^{-1}\right)$ is the thermal vapor flux, and $q_{V a}\left(\mathrm{~kg} \mathrm{~m}^{-2} \mathrm{~s}^{-1}\right)$ is the advective vapor flux.

[9] Combining the governing equations for liquid water and vapor flow leads to the governing differential equation for moisture transfer:

$$
\begin{aligned}
& \frac{\partial}{\partial t}\left(\rho_{L} \theta+\rho_{V} \theta_{a}\right)=-\frac{\partial}{\partial z}\left(q_{L h}+q_{L T}+q_{L a}\right)-\frac{\partial}{\partial z}\left(q_{V h}+q_{V T}+q_{V a}\right) \\
& =\rho_{L} \frac{\partial}{\partial z}\left[K_{L h}\left(\frac{\partial h}{\partial z}+1\right)+\left(K_{L T}+D_{T D}\right) \frac{\partial T}{\partial z}+\frac{K_{L h}}{\gamma_{w}} \frac{\partial P_{g}}{\partial z}\right] \\
& \quad+\frac{\partial}{\partial z}\left[D_{v h} \frac{\partial h}{\partial z}+D_{v T} \frac{\partial T}{\partial z}+D_{v a} \frac{\partial P_{g}}{\partial z}\right]
\end{aligned}
$$

where $D_{v h}\left(\mathrm{~kg} \mathrm{~m}^{-2} \mathrm{~s}^{-1}\right)$ is the isothermal vapor conductivity, $D_{v T}\left(\mathrm{~kg} \mathrm{~m}^{-1} \mathrm{~s}^{-1}{ }^{\circ} \mathrm{C}^{-1}\right)$ is the thermal vapor diffusion coefficient, and $D_{v a}$ (s) is the advective vapor transfer coefficient.

$$
D_{v h}=\left(D_{e}+D_{V g}\right) \frac{\partial \rho_{V}}{\partial h}, \quad D_{v a}=\rho_{V} \frac{S_{a} k_{g}}{\mu_{a}}, \quad D_{v T}=\left(D_{e}+D_{V g}\right) \frac{\partial \rho_{V}}{\partial T} .
$$

\subsubsection{Dry Air Equation}

[10] Dry air transport in unsaturated soil is driven by two main gradients, the dry air concentration or density gradient and the air pressure gradient. The first one diffuses dry air in soil pores, while the second one causes advective flux of dry air. At the same time, the dispersive transfer of dry air should also be considered. In addition, considering the mechanical and chemical equilibriums, a certain amount of dry air will dissolve into liquid according to Henry's law. Considering the above four effects, the balance equation for dry air may be presented as [Thomas and Sansom, 1995]

$$
\begin{gathered}
\frac{\partial}{\partial t}\left[\varepsilon \rho_{d a}\left(S_{a}+H_{c} S_{r}\right)\right]=-\frac{\partial q_{a}}{\partial z} \\
q_{a}=-D_{e} \frac{\partial \rho_{d a}}{\partial z}-\rho_{d a} \frac{S_{a} k_{g}}{\mu_{a}} \frac{\partial P_{g}}{\partial z}-D_{V g} \frac{\partial \rho_{d a}}{\partial z}+H_{c} \rho_{d a} \frac{q_{L}}{\rho_{L}},
\end{gathered}
$$

where $q_{a}\left(\mathrm{~kg} \mathrm{~m}^{-2} \mathrm{~s}^{-1}\right)$ is the dry air flux and $H_{c}(0.02$ for air at $1 \mathrm{~atm}$ and $25^{\circ} \mathrm{C}$ ) is Henry's constant. On the righthand side of equation (12), the first term depicts diffusive flux (Fick's law), the second term depicts advective flux (Darcy's law), the third depicts dispersive flux (Fick's law), and the fourth depicts advective flux due to dissolved air (Henry's law). Considering that dry air density is a function of matric potential, temperature, and air pressure, equation (12) could be rewritten with three state variables. Combining equation (12) with equation (11), the governing equation for dry air can be expressed as

$$
\begin{aligned}
& \frac{\partial}{\partial t}\left[\varepsilon \rho_{d a}\left(S_{a}+H_{c} S_{r}\right)\right]=-\frac{\partial}{\partial z}\left(q_{a h}+q_{a T}+q_{a a}\right) \\
& =\frac{\partial}{\partial z}\left[\left(K_{a h} \frac{\partial h}{\partial z}+H_{c} \rho_{d a} K_{L h}\right)+K_{a T} \frac{\partial T}{\partial z}+K_{a a} \frac{\partial P_{g}}{\partial z}\right],
\end{aligned}
$$

where $q_{a h}\left(\mathrm{~kg} \mathrm{~m}^{-2} \mathrm{~s}^{-1}\right)$ is the isothermal air flux, $q_{a T}$ $\left(\mathrm{kg} \mathrm{m}^{-2} \mathrm{~s}^{-1}\right)$ is the thermal air flux, $q_{a a}\left(\mathrm{~kg} \mathrm{~m}^{-2} \mathrm{~s}^{-1}\right)$ is the advective flux, and

$$
\begin{gathered}
K_{a h}=\left(D_{e}+D_{V g}\right) \frac{\partial \rho_{d a}}{\partial h}+H_{c} \rho_{d a} K_{L h}, \\
K_{a T}=\left(D_{e}+D_{V g}\right) \frac{\partial \rho_{d a}}{\partial T}+H_{c} \rho_{d a}\left(K_{L T}+D_{T D}\right), \\
K_{a a}=\left(D_{e}+D_{V g}\right) \frac{\partial \rho_{d a}}{\partial P_{g}}+\rho_{d a}\left(\frac{S_{a} k_{g}}{\mu_{a}}+H_{c} \frac{K_{L h}}{\gamma_{w}}\right) .
\end{gathered}
$$

\subsubsection{Energy Equation}

[11] In the vadose zone, the mechanisms for energy transport include conduction and convection. The conductive heat transfer contains the contribution from liquids, solids, and gas. Conduction is the main mechanism for heat transfer in soil and contributes to the energy conservation by solids, liquids, and air. Advective heat in soil is conveyed by liquid flux, vapor flux, and dry air flux. On the other hand, heat storage in soil includes the bulk volumetric heat content, the latent heat of vaporization, and a source term associated with the exothermic process of wetting of a porous medium (integral heat of wetting) [de Vries, 1958]. Accordingly, following the general approach by de Vries [1958], the energy balance equation in unsaturated soil may be written as four parts:

Solid

$$
\frac{\partial\left[\rho_{s} \theta_{s} c_{s}\left(T-T_{r}\right)\right]}{\partial t}=\frac{\partial}{\partial z}\left(\lambda_{s} \theta_{s} \frac{\partial T}{\partial z}\right),
$$

Liquid

$$
\frac{\partial\left[\rho_{L} \theta c_{L}\left(T-T_{r}\right)\right]}{\partial t}=\frac{\partial}{\partial z}\left(\lambda_{L} \theta \frac{\partial T}{\partial z}\right)-\frac{\partial}{\partial z}\left[q_{L} c_{L}\left(T-T_{r}\right)\right],
$$

Air and Vapor

$$
\begin{gathered}
\frac{\partial}{\partial t}\left[\left(\rho_{d a} c_{a}+\rho_{V} c_{V}\right) \theta_{a}\left(T-T_{r}\right)+\rho_{V} L_{0} \theta_{a}\right]=\frac{\partial}{\partial z}\left(\lambda_{g} \theta_{a} \frac{\partial T}{\partial z}\right) \\
-\frac{\partial}{\partial z}\left\{q_{V}\left[c_{V}\left(T-T_{r}\right)+L_{0}\right]+q_{a} c_{a}\left(T-T_{r}\right)\right\},
\end{gathered}
$$

Heat of wetting

$$
H_{w}=-\rho_{L} W \frac{\partial \theta}{\partial t}
$$

where $\lambda_{s}, \lambda_{L}$, and $\lambda_{g}\left(\mathrm{~W} \mathrm{~m}^{-1}{ }^{\circ} \mathrm{C}^{-1}\right)$ represent the thermal conductivities of solids, liquids, and pore air, respectively; $\theta_{s}$ (constant) is the volumetric content of solids in the soil; 
$c_{s}, c_{L}, c_{a}$, and $c_{v}\left(\mathrm{~J} \mathrm{~kg}^{-1}{ }^{\circ} \mathrm{C}^{-1}\right)$ are the specific heat of solids, liquids, air, and vapor, respectively; $T_{r}\left({ }^{\circ} \mathrm{C}\right)$ is the reference temperature; $\rho_{s}\left(\mathrm{~kg} \mathrm{~m}^{-3}\right)$ is the density of solids in the soil; $L_{0}\left(\mathrm{~J} \mathrm{~kg}^{-1}\right)$ is the latent heat of vaporization of water at temperature $T_{r}$; and $W\left(\mathrm{~J} \mathrm{~kg}^{-1}\right)$ is the differential heat of wetting (the amount of heat released when a small amount of free water is added to the soil matrix). The latent heat of vaporization varies with $T$ according to [Saito et al., 2006]

$$
L(T)=L_{0}-\left(c_{L}-c_{v}\right)\left(T-T_{r}\right) \approx 2.501 \times 10^{6}-2369.2 T .
$$

[12] According to equation (14), the conservation equation for energy transfer in the soil is given as

$$
\begin{aligned}
& \frac{\partial}{\partial t}\left[\left(\rho_{s} \theta_{s} c_{s}+\rho_{L} \theta c_{L}+\rho_{d a} \theta_{a} c_{a}+\rho_{V} \theta_{a} c_{V}\right)\left(T-T_{r}\right)+\rho_{V} L_{0} \theta_{a}\right] \\
& \quad-\rho_{L} W \frac{\partial \theta}{\partial t} \\
& =\frac{\partial}{\partial z}\left(\lambda_{\mathrm{eff}} \frac{\partial T}{\partial z}\right)-\frac{\partial}{\partial z}\left\{q_{L} c_{L}\left(T-T_{r}\right)+q_{V}\left[L_{0}+c_{V}\left(T-T_{r}\right)\right]\right. \\
& \left.\quad+q_{a} c_{a}\left(T-T_{r}\right)\right\}
\end{aligned}
$$

where $\lambda_{\text {eff }}\left(\mathrm{W} \mathrm{m}^{-1} \mathrm{~K}^{-1}\right)$ is the effective thermal conductivity, combining the thermal conductivity of solid particles, liquid, and dry air in the absence of flow. The parameters in the first term on the left-hand side of equation (15) and $\lambda_{\text {eff }}$ can be determined by de Vries' [1958] scheme. With the constitutive equations (see Appendix A), equations (10), (13), and (15) are solved jointly with specified boundary and initial conditions of the solution domain to obtain spatial and temporal variations of the three prime variables $h$, $T$, and $P_{g}$.

\subsection{Boundary Conditions}

\subsubsection{Boundary Conditions Formulation}

[13] For the specific case here, no ponding or surface runoff is considered. This means that the moisture flux out of soil is always equal to evaporation minus precipitation.

$$
\left.q_{m}\right|_{z=0}=E-\rho_{L} P,
$$

where $E\left(\mathrm{~kg} \mathrm{~m}^{-2} \mathrm{~s}^{-1}\right)$ is the evaporation rate and $P\left(\mathrm{~m} \mathrm{~s}^{-1}\right)$ is the precipitation rate. Considering the aerodynamic resistance and soil surface resistance to water vapor transfer from the soil to the atmosphere, the evaporation is expressed as

$$
E=\frac{\rho_{v s}-\rho_{v a}}{r_{a}+r_{s}},
$$

where $\rho_{v s}\left(\mathrm{~kg} \mathrm{~m}^{-3}\right)$ is the water vapor density at the soil surface, $\rho_{v a}\left(\mathrm{~kg} \mathrm{~m}^{-3}\right)$ is the atmospheric vapor density, $r_{s}\left(\mathrm{~s} \mathrm{~m}^{-1}\right)$ is the soil surface resistance to water vapor flow [Camillo and Gurney, 1986], and $r_{a}\left(\mathrm{~s} \mathrm{~m}^{-1}\right)$ is the aerodynamic resistance [Campbell, 1985]. Equation (16) is the surface boundary condition for moisture transport. Without taking ponding and surface runoff into consideration, the soil surface is open to the atmosphere, and the measured atmospheric pressure is adopted as the surface boundary condition for dry air transport in the soil. The measured soil surface temperature is set as the boundary condition for heat transport.
[14] In the Badain Jaran Desert, according to Gates et al. [2008], the thickness of unsaturated zone ranges from less than $1 \mathrm{~m}$ in interdune areas to approximately $400 \mathrm{~m}$ on large dunes. In this study, the length of the soil column is set to be $5 \mathrm{~m}$. The bottom boundary condition for the moisture equation is set to be free drainage (unit hydraulic head gradient). Considering the diurnal variation scale, the temperature gradient and the air pressure gradient at the bottom of the column are specified to be zero. A one-dimensional setting is adopted in this study, predominantly considering the vertical interactive process between the atmosphere and the soil [Milly and Eagleson, 1980]. The initial soil matric head and soil temperature are determined by interpolating the measured values at midnight on 12 June 2008 between measurement depths. The initial soil air pressure is set as the daily average atmospheric pressure during the selected 6 day period.

\subsubsection{Meteorological Forcing Data}

[15] The field measurement was conducted between $39^{\circ} 45^{\prime} 20^{\prime \prime} \mathrm{N}$ and $39^{\circ} 47^{\prime} 27^{\prime \prime} \mathrm{N}$ and $102^{\circ} 27^{\prime} 7^{\prime \prime} \mathrm{E}$ and $102^{\circ} 28^{\prime} 58^{\prime \prime} \mathrm{E}$. Although all the meteorological variables are available from observation records, it is still difficult to solve the above-described model at the time interval the meteorological variables were recorded. There is a need to use a simple approach to generate a continuous value for the meteorological variables from available daily information.

[16] In terms of a balance between computational efficiency and solution accuracy, the time step is required to be small enough so that the moisture content and the temperature do not exceed a prescribed limit [Milly and Eagleson, 1980]. This means that the time step is adjusted automatically during computing (1-1800 s). Accordingly, the time interval of the meteorological inputs should be adjusted to match the new time step. In this study, the Fourier transform method was used to approximate the frequency domain representation of the meteorological forcing data and produced the forcing data continuously.

[17] Figure 1 shows the measurement and the approximation of meteorological variables, including air temperature, relative humidity, wind speed, precipitation, atmospheric pressure, and soil surface temperature, measured in the Badain Jaran Desert with a height of $2 \mathrm{~m}$ above the soil surface and an interval of $30 \mathrm{~min}$ from 13 to 19 June 2008. The 6 day data were chosen to include a rainfall event at the end of the first day of the selected period. Except for wind speed data, which fluctuated irregularly because of inherent randomness, records of other variables showed clearly typical diurnal behaviors. The precipitation occurred at midnight and interrupted the smooth variation of most variables except the surface temperature.

[18] Figure 1a shows that the average air temperature was $24.3^{\circ} \mathrm{C}$ one day before rainfall and $20.4^{\circ} \mathrm{C}$ one day after. From that day on, the average air temperature increased to $28.7^{\circ} \mathrm{C}$ at the end of the selected period. As can be seen in Figure $1 \mathrm{~b}$, the average daily relative humidity was 0.31 and 0.51 before and after rainfall, respectively, followed by a 3 day gradual decrease to 0.14 and a slight increase on the final day to 0.21 . With the air temperature and the relative humidity, the diurnal variation of the atmospheric vapor pressure could be easily determined (not shown here). As can be seen in Figure 1e, the atmospheric pressure followed the same variation pattern as the relative 

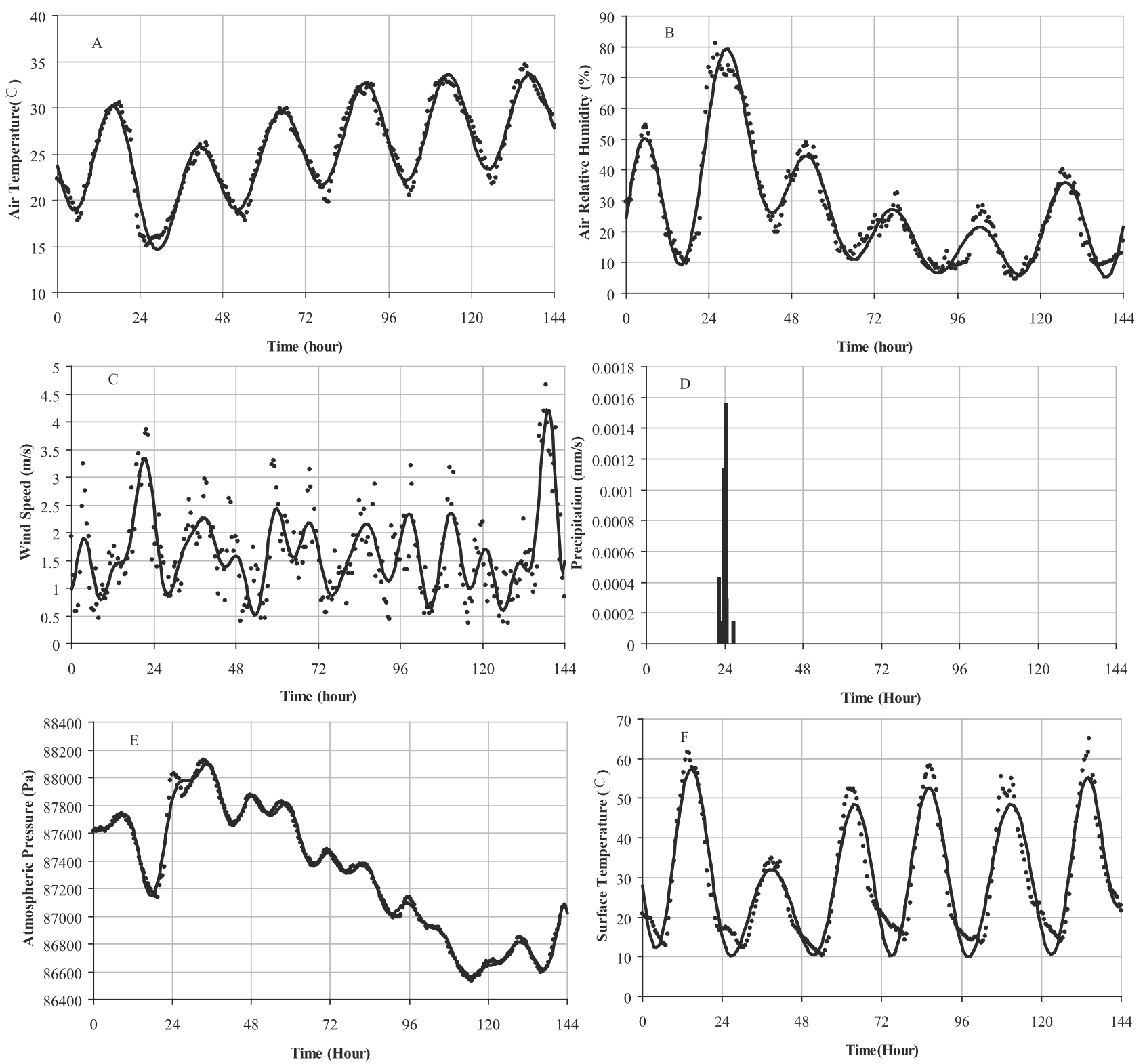

Figure 1. Diurnal change of meteorological variables: (a) air temperature, (b) relative humidity, (c) wind speed, (d) precipitation, (e) atmospheric pressure, and (f) surface temperature. They are recorded every $30 \mathrm{~min}$ from 13 to 19 June 2008. The solid line is the approximation, and the dots are the measurement.

humidity did. The daily average atmospheric pressure was 87,528.8 and 87,907.2 Pa before and after the precipitation, respectively. From the second day on, the average atmospheric pressure decreased to $86,791.3 \mathrm{~Pa}$ on the fifth day and increased to $86,753.21 \mathrm{~Pa}$ on the last day.

[19] Following van de Griend and Owe [1994], the aerodynamic resistance $r_{a}$ and soil surface resistance $r_{s}$ may be expressed as

$\begin{aligned} r_{a} & =\frac{1}{k^{2} U}\left[\ln \left(\frac{z_{m}-d-z_{\text {om }}}{z_{\text {om }}}\right)-\psi_{s m}\right]\left[\ln \left(\frac{z_{m}-d-z_{o h}}{z_{o h}}\right)-\psi_{s h}\right], \\ r_{s} & =r_{s l} e^{a\left(\theta_{\min }-\theta_{\text {sur }}\right)},\end{aligned}$ where $k$ is the von Karman constant (0.41), $U\left(\mathrm{~m} \mathrm{~s}^{-1}\right)$ is the measured wind speed at a certain height, $Z_{m}(\mathrm{~m})$ is the height of the wind speed measurement, $d(\mathrm{~m})$ is the zeroplane displacement ( 0 for bare soil), $Z_{o m}(0.001 \mathrm{~m})$ is the surface roughness length for momentum flux, $\psi_{s m}$ is the atmospheric stability correction factor for momentum flux, $Z_{\text {oh }}(0.001 \mathrm{~m})$ is the surface roughness length for heat flux, $\psi_{s h}$ is the atmospheric stability correction factor for heat flux, $r_{s l}\left(10 \mathrm{~s} \mathrm{~m}^{-1}\right)$ is the resistance to molecular diffusion across the water surface itself, $a$ (35.63) is the fitted parameter, $\theta_{\min }\left(0.15 \mathrm{~m}^{-3} \mathrm{~m}^{3}\right)$ is the empirical minimum value above which the soil is able to deliver vapor at a potential rate, and $\theta_{\text {sur }}$ is the soil water content in the top soil layer. 


\subsection{Numerical Solution Algorithm}

[20] The governing differential equations are converted to nonlinear ordinary differential equations with unknowns as the independent variables at a finite number of nodes in Galerkin's method of weighted residuals. The nodal spacing is determined automatically with a spacing factor, which leads to 38 discretization nodes across the problem domain. The top surface layer has the smallest nodal space of $0.25 \mathrm{~cm}$, while the bottom layer has the biggest nodal space of $50 \mathrm{~cm}$. A finite difference time-stepping scheme is then applied to evaluate the time derivatives and is solved by a successive iterative linearization scheme (see Appendix B). The governing equations subject to the boundary and initial conditions were solved numerically by an authordeveloped script with MATLAB (version 7.4, The MathWorks, Natick, Massachusetts). To achieve the desired convergence criteria, the prescribed upper limits of independent variables are used to determine a new time step size automatically [Milly, 1982] in the form of

$\Delta t=\min \left[\frac{X_{\max }}{\max _{i}\left(\frac{\mathrm{d} \theta_{i}}{\mathrm{~d} t}\right)}, \frac{T_{\max }}{\max _{i}\left(\frac{\mathrm{d} T_{i}}{\mathrm{~d} t}\right)}, \frac{P_{g_{\max }}}{\max _{i}\left(\frac{\mathrm{d} P_{g_{i}}}{\mathrm{~d} t}\right)}, \frac{h_{\max }}{\max _{i}\left(\frac{\mathrm{d} h_{i}}{\mathrm{~d} t}\right)}\right]$,

where $\max _{i}$ denotes maximization over all nodes $i$, the changes of state variables are estimated from the most recent time step, and $X_{\max }, T_{\max }, P_{\text {gmax }}$, and $h_{\max }$ are the upper limits of change for volumetric water content, temperature, atmospheric pressure, and matric potential, respectively. If the change exceeds the desired upper limits, the calculation of that time step is erroneous, and the time step will be repeated with a decreased time length. By doing this, a reasonable tradeoff between the computational effort and the accuracy of the solution should be achieved.

\subsection{Comparison With Measurements}

[21] The field measurement of soil moisture and temperature has been described by Zeng et al. [2009]. The soil moisture was measured at depths of 10,20,30,40, and $50 \mathrm{~cm}$ by a soil water content profile sensor (EasyAG50, Sentek Pty., Ltd., Stepny, Australia). The soil temperature was measured at depths of $2,5,10,20$, and $50 \mathrm{~cm}$ by a soil temperature profile sensor (STP01, Hukseflux Thermal Sensors B.V., Delft, Netherlands). According to Figure 2, there is a reasonably good agreement between simulated and measured soil temperatures at different depths. The simulation matched the diurnal variations on most days. Obviously, the accuracy is not always good. The underestimation at $2 \mathrm{~cm}$ during the whole simulation period can contribute to the Fourier-transformed surface temperature in Figure 1f. There is also overestimation at other depths and other days, for example, on day 1 at depths of 10, 20, and $50 \mathrm{~cm}$ and days 5 and 6 at depths of 10 and $20 \mathrm{~cm}$.

[22] The quality of the soil moisture measurement has been quantitatively assessed and calibrated by Zeng et al. [2009]. The major concern about the measurement of soil moisture in the sand is the temperature effect. The temperature effects for the moisture sensors were $14.4 \%$ of readings from $12^{\circ} \mathrm{C}$ to $45^{\circ} \mathrm{C}$ at $10 \mathrm{~cm}, 13.9 \%$ from $11^{\circ} \mathrm{C}$ to

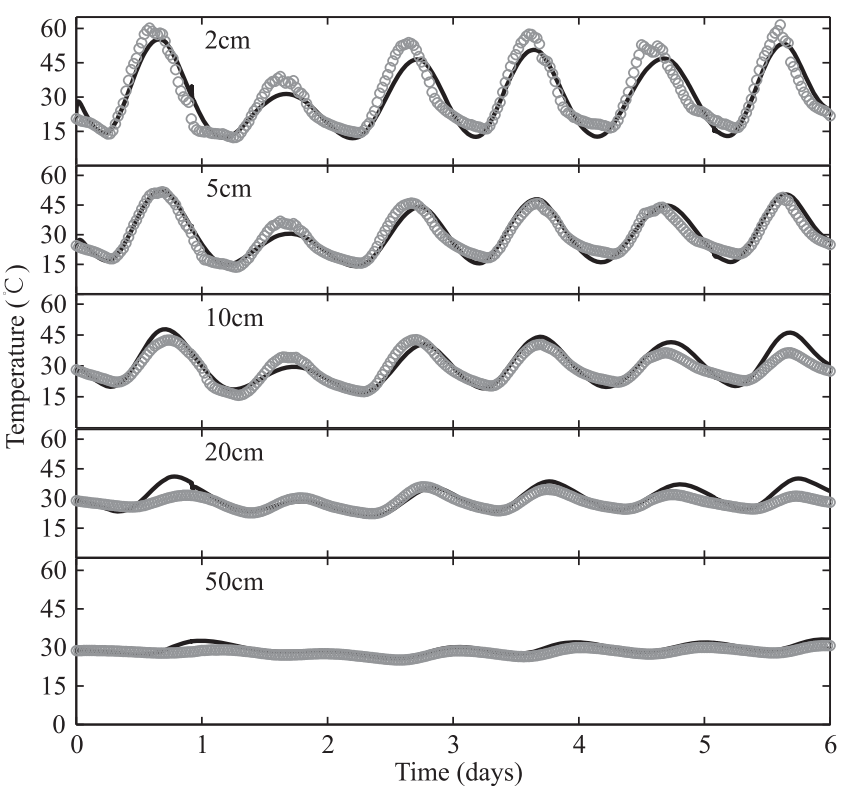

Figure 2. Comparison between simulated and measured soil temperatures at selected depths during 13-19 June 2008. The solid line is the simulation, and the gray open circles are the measurement.

$50^{\circ} \mathrm{C}$ at $20 \mathrm{~cm}, 14 \%$ from $9^{\circ} \mathrm{C}$ to $51^{\circ} \mathrm{C}$ at $30 \mathrm{~cm}, 13 \%$ from $9^{\circ} \mathrm{C}$ to $55^{\circ} \mathrm{C}$ at $40 \mathrm{~cm}$, and $15 \%$ of readings from $8^{\circ} \mathrm{C}$ to $55^{\circ} \mathrm{C}$ at $50 \mathrm{~cm}$, respectively. After the calibration, the temperature effects at depths of $10,20,30,40$, and $50 \mathrm{~cm}$ were reduced by $92 \%, 93 \%, 93.8 \%, 88 \%$, and $82 \%$, respectively [Zeng et al., 2009].

[23] Compared to the good simulation of the temperature, the soil moisture simulation produces no good matches to the measurements, except for at depths of 10 and $50 \mathrm{~cm}$ (Figure 3). At a depth of $10 \mathrm{~cm}$, the simulation captures the important trend, which is the response of soil moisture to the precipitation at the end of day 1 . However, the measurements at depths of 20,30 , and $40 \mathrm{~cm}$ do not follow this trend as the simulation does. It partially indicates that the parameters in soil hydraulic properties, assumed to be vertically homogeneous, are likely not correct. The low sensitivity of the soil moisture sensor in detecting moisture content in extremely dry environments [Vereecken et al., 2008] is another possible reason for the mismatch. Further investigation should be made to quantify the heterogeneity of the sand at the field site. The numerical solution for the soil moisture in the shallow layer $(10-20 \mathrm{~cm})$ is not smooth enough. It is related to the determination of the time step, which is controlled by $X_{\max }, T_{\max }, P_{\text {gmax }}$, and $h_{\max }$. The smoothness can be increased by decreasing the upper limit of change for state variables in equation (19), which would lead to a smaller time step and higher computation cost.

\section{Results and Analysis}

\subsection{Advective Effect on Evaporation}

[24] With equations (10), (13), and (15), the water flux in a two-phase heat and mass flow field can be identified as the isothermal flux, the thermal flux, and the advective flux. With the exclusion or inclusion of thermal and advective 


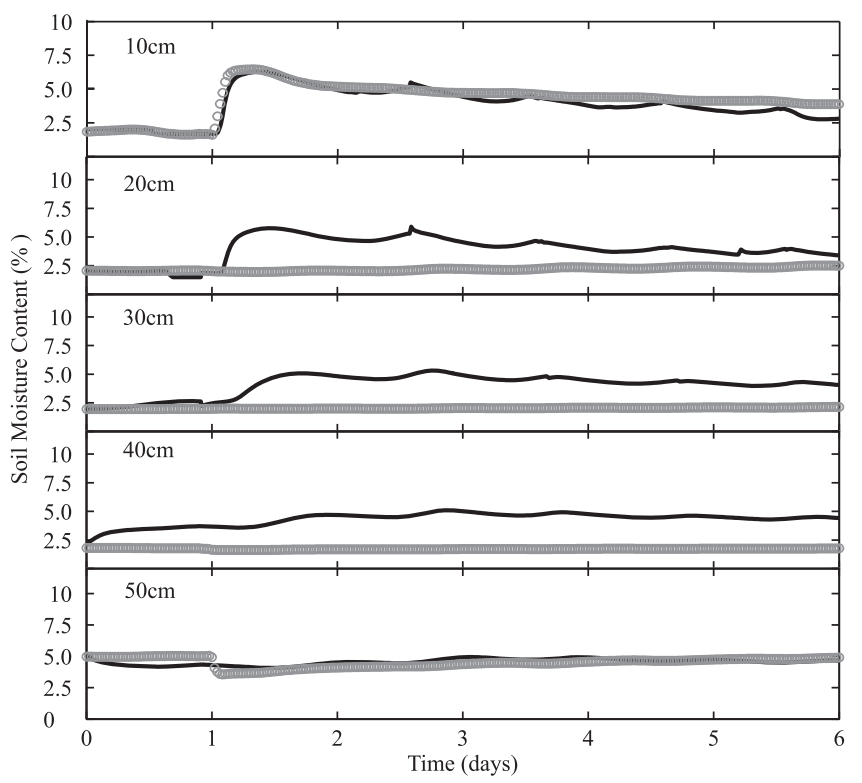

Figure 3. Same as Figure 2, but for soil moisture content at selected depths. The solid line is the simulation, and the gray open circles are the measurement.

fluxes, the thermal effect and advective effect on evaporation can be investigated. The thermal effect on evaporation has been studied in detail by Milly [1984a, 1984b] with linear and simulation analysis. However, in Milly's analysis, the transport coefficient for adsorbed liquid flow due to the thermal gradient $D_{T D}$ was not taken into account, although it was included in Milly's formulation [Milly, 1982; Prunty, 2009]. We found that neglecting $D_{T D}$ gives rise to errors in the calculated evaporation because of the intensive changes of the temperature gradient at the soil surface. The magnitude of order of the daily average evaporation was overestimated by about $2.3 \%$ (results not shown here). The overestimation error deduced by neglecting $D_{T D}$ occurs during the daytime because the soil was warming and hence the adsorbed liquid flow due to the temperature gradient was directed downward. During the nighttime, the evaporation is underestimated by neglecting $D_{T D}$, but the error is negligibly small. For further understanding of the thermal effect on evaporation, readers are referred to Milly [1984a, 1984b]. With the foregoing introduction in mind, this study is limited to the advective effect on evaporation.

[25] According to the particle size distribution curve [Zeng et al., 2009], the sand in the field was defined as fine sand, which means that $K_{s}$ would be on the order of $10^{-6}$ to $10^{-3} \mathrm{~cm} \mathrm{~s}^{-1}$ [Bear, 1972]. In order to check the impact of $K_{s}$ on the advective effect on evaporation, both high $K_{s}\left(2 \times 10^{-3} \mathrm{~cm} \mathrm{~s}^{-1}\right)$ and low $K_{s}\left(7.87 \times 10^{-4} \mathrm{~cm} \mathrm{~s}^{-1}\right)$ were used. The high $K_{s}$ is determined by soil water characteristics [Saxton and Rawls, 2006] with a bulk density of $1.67 \mathrm{~g} \mathrm{~cm}^{-3}$ and solid matter of $96 \%$ sand and $2 \%$ clay. The low $K_{s}$ is calculated inversely by fitting the measurement of the soil water content at a depth of $20 \mathrm{~cm}$. The $r^{2}$ for the regression of the prediction and observation of soil moisture is 0.66. For this purpose, the inverse solution of HYDRUS1D, version 4.09 (http://www.hydrus2d.com), was employed.

[26] In Figure 4, the impact of neglecting advective fluxes on calculated evaporation is shown. Both plots indicate that neglecting the advective fluxes underestimates the diurnal evaporation. In the high-permeability soil, neglecting it leads to underestimation error in computed daily average evaporation ( 6 day period) on the order of $6.4 \%$. However, with respect to the day right after the rainfall event (second day of the selected period), the underestimation error in computed diurnal evaporation is high and reaches $33.3 \%$. As for the low-permeability soil, the error induced by neglecting the advective flux in the daily average evaporation is $8.85 \%$, and the error in the diurnal evaporation on the second day reaches $53.3 \%$. The advective effect is much more evident in the low-permeability soil than in the high-permeability soil. The high permeability leads to high soil air velocity. The diurnal average evaporation with airflow in the high-permeability soil on the second day is 3.35 $\times 10^{-6} \mathrm{~g} \mathrm{~cm}^{-2} \mathrm{~s}^{-1}$, compared to $2.85 \times 10^{-6} \mathrm{~g} \mathrm{~cm}^{-2} \mathrm{~s}^{-1}$ in the low-permeability soil. However, the high air velocity means the soil air pressure can equilibrate quickly with the atmospheric pressure, which will result in a small air pressure gradient in the soil. This is the reason that the advective effect is relatively weaker in the high-permeability soil while strong in the low-permeability soil.
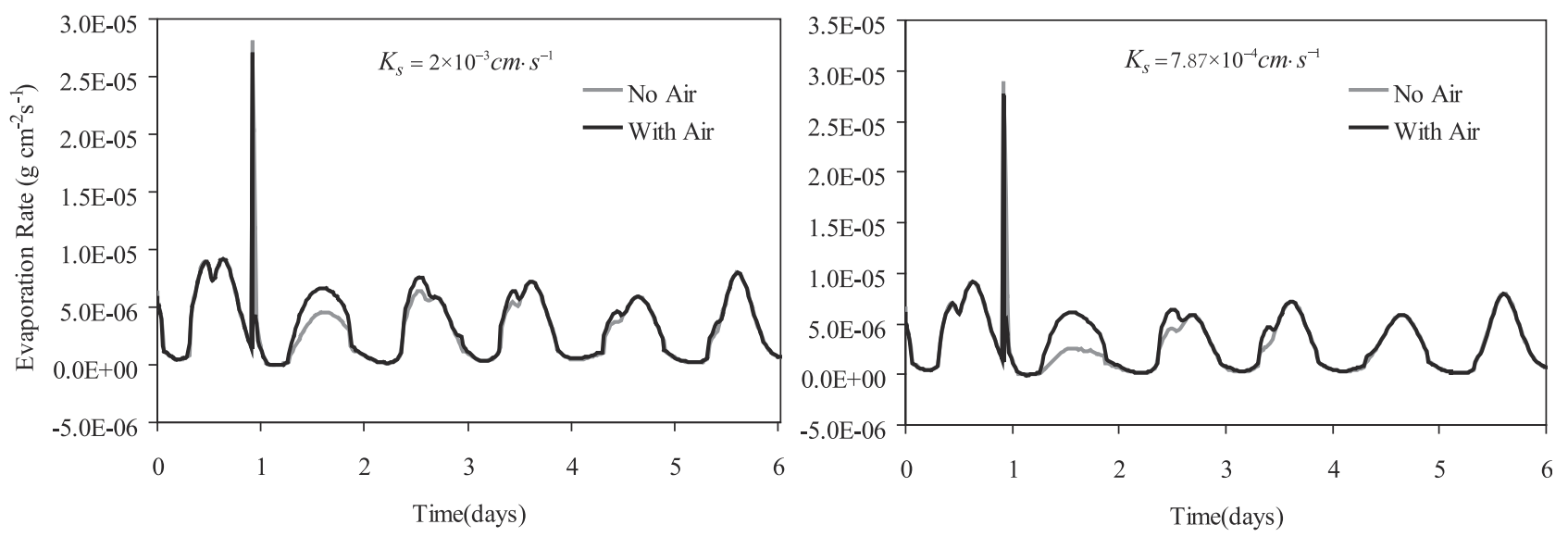

Figure 4. Advective effects on the diurnal evaporation in both high- and low-permeability soils. 


\subsection{Driving Forces Considering Air Flow}

[27] The strong or weak advective effect in different soils can be recognized by the soil air pressure head gradient field. Figures $5 \mathrm{a}$ and $5 \mathrm{~b}$ show the scaled color maps of the soil air pressure head gradient field (described positive upward) in both the high- and low-permeability soils. The diurnal variation patterns of soil air pressure head gradient in both soils are similar. In the shallow subsurface layer (from the surface to a depth of $20 \mathrm{~cm}$ ), the gradient is downward during the daytime (roughly from 7:30 A.M. to 7:00 P.M.) and upward during the nighttime (roughly from 7:00 P.M. to 7:30 A.M.). The fluctuation of pressure head gradient in the deeper soil (below a depth of $20 \mathrm{~cm}$ ) follows the pattern in the shallow layer, albeit with a time delay and damped amplitude. At a depth of $50 \mathrm{~cm}$, the fluctuation of the air pressure has a daily average time delay of $2 \mathrm{~h}$. The maximum air pressure gradient damps from $2.5 \mathrm{~cm}$ (at the surface) to $0.71 \mathrm{~cm}$ in the high-permeability soil and from 6.3 to $1.73 \mathrm{~cm}$ in the low-permeability soil. As seen in Figures $5 \mathrm{a}$ and $5 \mathrm{~b}$, the amplitude of the air pressure head gradients in the high-permeability soil $(-4.3$ to $\sim 2.5 \mathrm{~cm})$ is at least 2 times smaller than that in the low-permeability soil $(-8$ to $\sim 6.3 \mathrm{~cm})$. This can be identified easily from the weak color contrast in Figure 5a and the strong color

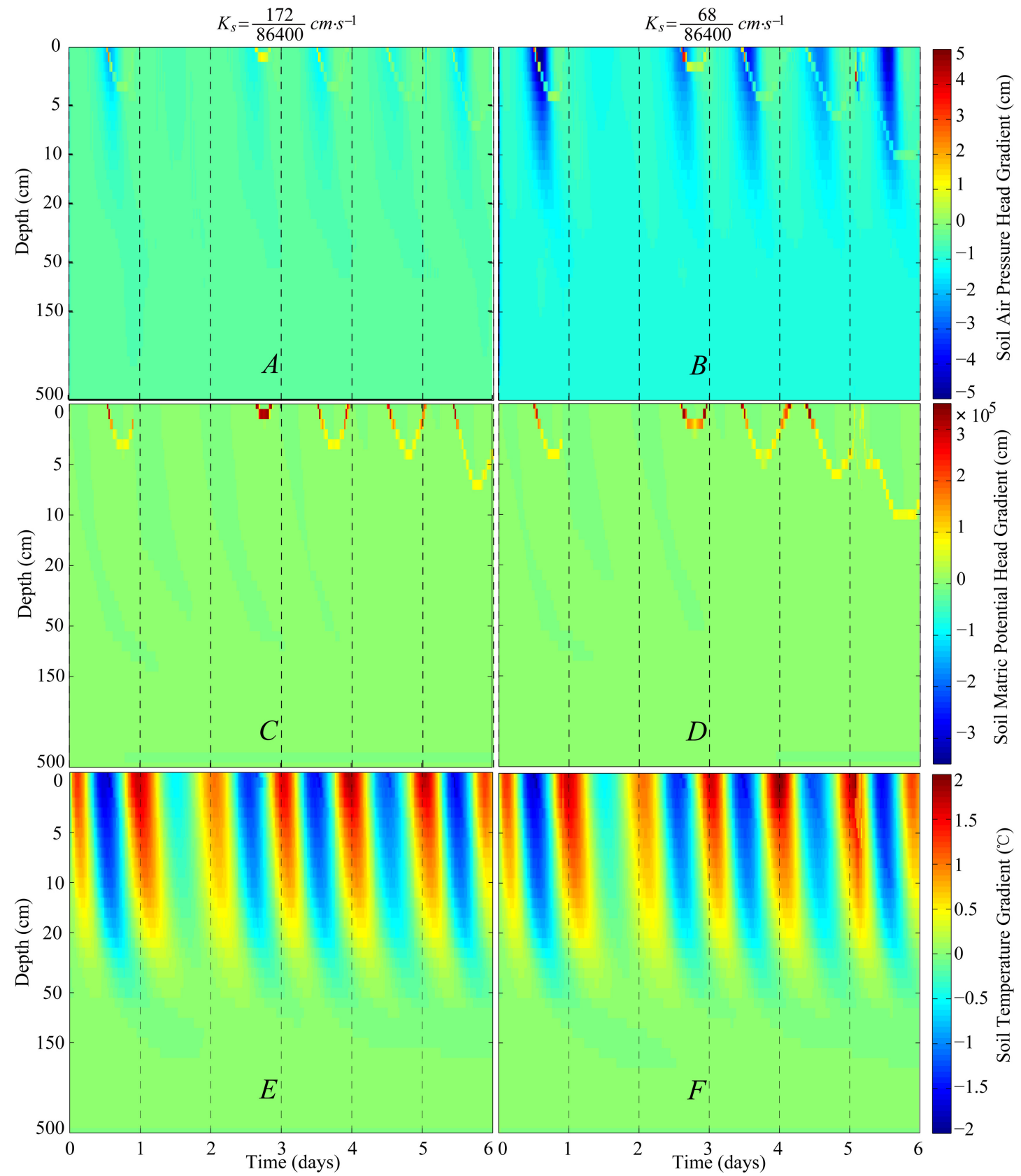

Figure 5. Spatial and temporal distributions of $(\mathrm{a}, \mathrm{b})$ soil air pressure head gradient, $(\mathrm{c}, \mathrm{d})$ soil matric potential head gradient, and (e, f) soil temperature gradient in both the high- and low-permeability soils when the airflow is considered. 
contrast in Figure 5b. This indicates that in the high-permeability soil the air pressure can equilibrate quickly with the atmospheric pressure, which minifies the air pressure head gradients and leads to a small advective effect. It follows the description that the higher the permeability, the lower the air pressure gradient is [Tillman and Smith, 2005, Figure 4].

[28] In Figures 5a and 5b, there are embedded upward gradients presented at the surface around the middle of the selected days, except for the second day, which is right after the rainfall event. The embedded upward gradients propagate into the shallow soil layer and vanish back to the surface near midnight. They actually correspond to the sharp upward matric potential head gradient induced by the drying of the shallow soil layer $(7 \mathrm{~cm}$ thick in the highpermeability soil and $10 \mathrm{~cm}$ thick in the low-permeability soil). Figures $5 \mathrm{c}$ and $5 \mathrm{~d}$ show the same pattern of an embedded sharp upward gradient in the soil matric potential head gradient field as the air pressure head gradient field does.

[29] The soil matric potential head gradient (described positive upward) in the soil layer above a depth of $50 \mathrm{~cm}$ varies diurnally, upward during the day and downward during the night. Below this layer, the gradient remains upward during the selected period. The fluctuation of the gradient has a time delay and damped amplitude. The strongest fluctuations in the shallow surface layer $(7 \mathrm{~cm}$ thick in the highpermeability soil and $10 \mathrm{~cm}$ thick in the low-permeability soil) are 2-5 orders of magnitude larger than those in the layer below. The huge differences in gradient fluctuation between the shallow surface layer and the layer underneath it make the scaled color maps only visible for the sharp upward gradients induced by the drying of the shallow surface layer. The match in the embedded upward gradients between Figures $5 \mathrm{a}$ and $5 \mathrm{~b}$ and Figures $5 \mathrm{c}$ and $5 \mathrm{~d}$ implies a relationship between the matric potential and the soil air pressure expressed by equation (4). During the drying of the shallow surface layer, the matric potential drops dramatically (absolute value increases steeply) and minifies the soil air pressure (absolute value decreases).

[30] Figures 5e and 5f show the scaled color maps of the soil temperature gradient field (described positive upward). There is no big difference in temperature gradient between the two soils. The fluctuation of the temperature gradient follows the general principle of downward during the day and upward during the night, with a time delay and damped amplitude. Below a depth of $50 \mathrm{~cm}$, the soil temperature remains almost stable, and the soil temperature gradient is less than $0.1^{\circ} \mathrm{C} \mathrm{cm}^{-1}$.

\subsection{Comparison of Driving Forces and Conductivities}

[31] According to Figure 4, it seems that the underestimation error of daily evaporation is due to the lack of upward advective fluxes during the daytime when the airflow is neglected. However, with the description of the diurnal variation of the soil air pressure gradient, which is downward during the day and upward during the night in the shallow soil layer (above a depth of $50 \mathrm{~cm}$ ), it is evident that the underestimation error is not directly induced by the advective fluxes.

[32] Considering the soil temperature gradient has a diurnal variation similar to the soil air pressure gradient, downward during the day and upward during the night, the soil matric potential gradient is the only driving force that can cause the underestimation error directly, which is upward during the day and downward during the night in the shallow soil layer (above a depth of $50 \mathrm{~cm}$ ). Then, it seems as if the relatively lower evaporative flux is initiated by the lower upward matric potential gradient, while the relatively higher evaporative flux is triggered by the higher upward matric potential gradient. Presumably, the upward matric potential gradient generated by including airflow should be greater than that generated by neglecting airflow because of the higher evaporative flux presented in the simulation including airflow.

[33] This is not the case, however (as can be seen in Figures $6 \mathrm{~b}$ and $8 \mathrm{~b}$ ). The upward potential gradient generated by neglecting airflow is larger than that generated by including airflow, which is the opposite of the presumption made above. There should be other factors contributing to the underestimation error, which may be the isothermal hydraulic conductivity and the isothermal vapor transport coefficient. Compensating the lower upward potential gradient, the isothermal hydraulic conductivity in the simulation considering airflow should be larger than that neglecting airflow, to have a relatively higher evaporative flux on the surface. Thus, the underestimation error induced by neglecting airflow can be demonstrated mechanically.

[34] On the other hand, it is possible to have an indirect reason for the underestimation error. For instance, when neglecting airflow, the downward thermal liquid and vapor fluxes are much higher than those when including airflow and thus suppress the evaporative flux on the surface, which causes the underestimation error. In the sections 3.3.1-3.3.3, the direct and indirect reasons will be analyzed through comparisons of the driving forces and the conductivities in different model runs.

\subsubsection{Normalized Scale Index}

[35] In order to investigate and verify the above discussion, there is a need to compare the gradients (soil matric potential gradient and soil temperature gradient) and the conductivities (thermal and isothermal hydraulic conductivities and vapor transport coefficients) with and without considering soil airflow. The comparison is implemented with a normalized scale index (NSI), which is calculated differently with respect to gradients and conductivity.

[36] For the soil temperature gradient, the NSI is calculated as

$$
\begin{aligned}
& \text { NSI }=\text { Average }[\text { Sum }(\text { GradDiff })] \\
& \text { GradDiff }= \pm \frac{\operatorname{Grad}_{\text {no_air }}}{\text { Grad }_{\text {air }}}
\end{aligned}
$$

where GradDiff is used to express the ratio of the gradient changed by neglecting airflow to that considering airflow and is positive for $\mathrm{Grad}_{\text {air }}, \mathrm{Grad}_{\text {no_air }}>0$ and negative for $\mathrm{Grad}_{\text {air }}, \mathrm{Grad}_{\text {no_air }}<0$. The NSI is the mean value of GradDiff at different depths during the selected period. Grad ${ }_{\text {air }}$ and $\mathrm{Grad}_{\text {no_air }}$ are the gradients generated with and without considering airflow, respectively. GradDiff is only calculated when both $\mathrm{Grad}_{\text {air }}$ and $\mathrm{Grad}_{\text {no_air }}$ are either positive or negative. Thus, the summation of GradDiff can show if the upward gradient or the downward gradient is dominant. The sign before the ratio of $\mathrm{Grad}_{\text {no_air }}$ to $\mathrm{Grad}_{\text {air }}$ indicates the direction of the gradient (positive upward). If the 


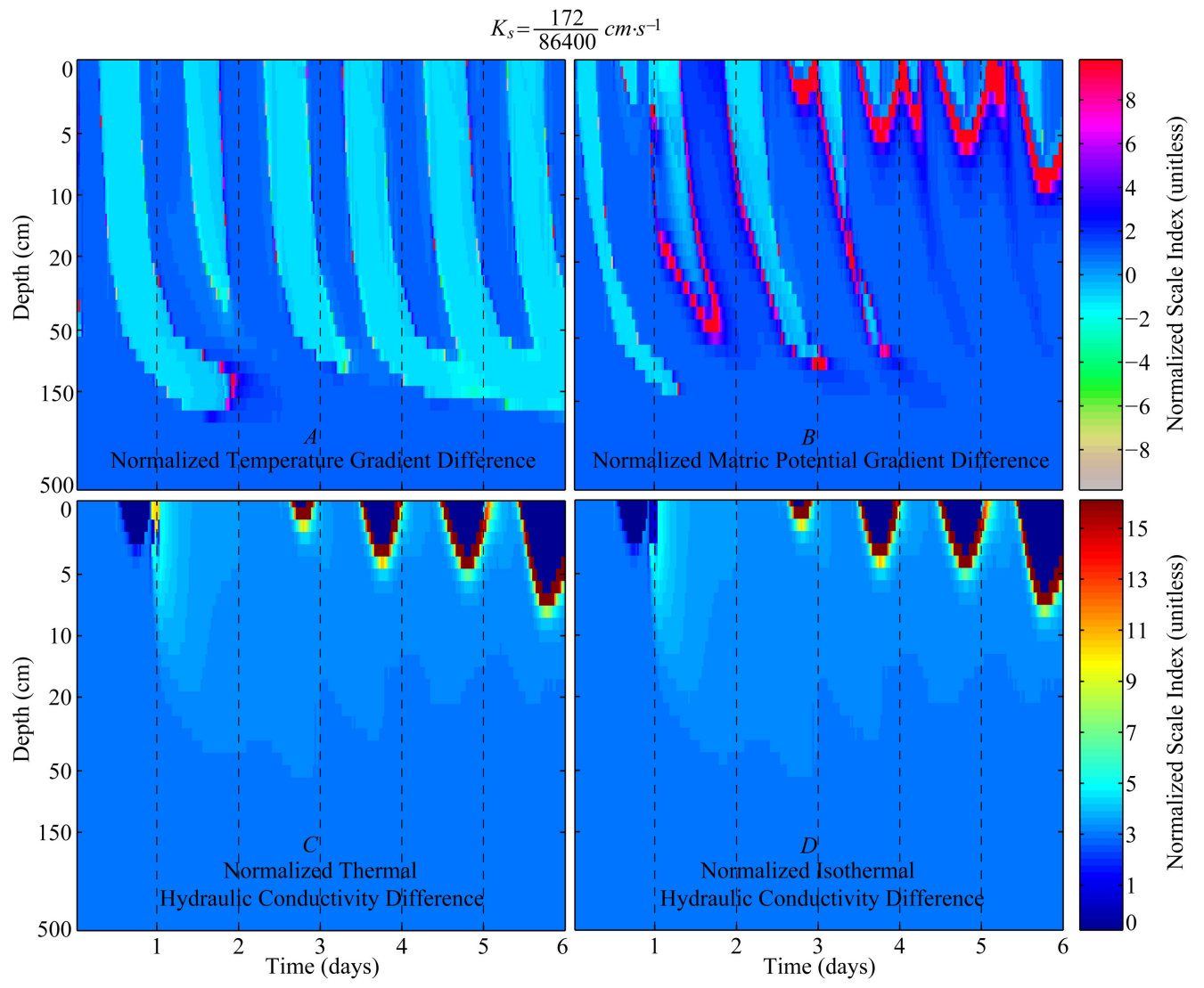

Figure 6. Spatial and temporal distributions of (a) normalized scale index for soil temperature gradient difference, (b) soil matric potential gradient difference, (c) thermal hydraulic conductivity difference, and (d) isothermal hydraulic conductivity difference induced by neglecting soil airflow in the highpermeability soil.

absolute value of GradDiff is less than 1, it means that the gradient induced by neglecting airflow is lower than that induced by including airflow and vice versa.

[37] For the conductivities, the NSI is calculated as

$$
\mathrm{NSI}=\text { Average }[\operatorname{Sum}(\text { CondDiff })], \text { CondDiff }=\frac{\text { Cond }_{\text {air }}}{\text { Cond }_{\text {no_air }}},
$$

where CondDiff is used to express the ratio of the conductivity changed by considering airflow to that neglecting airflow. Cond ${ }_{\text {air }}$ and Cond $\mathrm{no}_{\text {nair }}$ are the conductivities with and without airflow, respectively. There is no positive or negative sign before the ratio of $\mathrm{Cond}_{\text {no_air }}$ to Cond $_{\text {air }}$ because the conductivity is always positive.

\subsubsection{Comparison in the High-Permeability Soil}

[38] In the high-permeability soil, results are shown only for the comparison of the thermal and isothermal hydraulic conductivities. The reason for not showing the comparison results for the vapor transport coefficients is that they only differed significantly during the rainfall event. In the rest of the simulation period, the average NSI for the isothermal vapor transport coefficient is only 0.97 , which means the isothermal vapor transport coefficient with airflow is close to that without airflow. Another reason for not comparing the isothermal vapor transport coefficient is its small order of magnitude $\left(1 \times 10^{-12}\right)$, which is at least 6 orders of magnitude smaller than the hydraulic conductivities and the thermal vapor transport coefficient. The thermal vapor transport coefficient is not shown because of its small deviation induced by neglecting airflow (average NSI $=1.002$ ).

[39] Figure 6a shows the diurnal variation of the temperature gradient difference induced by neglecting airflow in the high-permeability soil. The average NSI of the soil temperature gradient difference throughout the soil profile is 0.21 . This indicates that the amplitude of the temperature gradient variation without airflow is lower than that with airflow (NSI is less than 1). When only the top surface layer is considered $(0.25 \mathrm{~cm}$ thick $)$, the larger temperature gradient in the simulation with airflow is much more evident, with an average NSI of 0.07 . The top surface layer is set to be $0.25 \mathrm{~cm}$ thick, which is accordant with the thickness of the top element in the discretization of the soil column. According to equation (20), the smaller the value of NSI (in the range of 0 to 1 ), the larger the temperature gradient with airflow is, compared to that without airflow. If only the day right after the rainfall event is selected, the difference between the temperature gradient is reduced, with a larger average NSI of 0.29 , because of the moist top surface layer. If only the period with a downward temperature gradient is selected, the average NSI is -0.21 , which means that the downward temperature gradient with airflow is higher than that without airflow. 
[40] The comparison of the temperature gradient demonstrates that the possible indirect reason for the underestimation error (higher downward thermal fluxes in the simulation without airflow) can only be attributed to the thermal conductivity for liquid and vapor. However, the thermal vapor transport coefficient remains almost unchanged during the whole simulation period. The thermal hydraulic conductivity should be the key factor for the indirect reason. The thermal hydraulic conductivity with airflow should be smaller than that without airflow, and the magnitude of the difference between them should be larger than the difference between soil temperature gradients in order to have a higher downward thermal flux to suppress the evaporation. This is not the case, however (as can be seen in Figures 7d and 9d). A detailed demonstration is as follows.

[41] Figure 6c shows the diurnal variation of the thermal hydraulic conductivity difference induced by neglecting airflow. It is easy to identify that the variation pattern is in agreement with the sharp variation of the soil matric potential (Figure 5c). Because of the extremely low soil matric potential (absolute value is extremely large) in the shallow surface layer during drying, the conductivity in the top layer is equal to zero (dark blue zones in Figure 6c), which means no thermal liquid flow in the top layer during the corresponding period occupied by dark blue zones. There is no dark blue zone in the day right after rainfall. This is also true for the isothermal hydraulic conductivity (Figure 6d). This partially explains the most significant advective effect (or underestimation error) occurring on the second day.

[42] During the second day, in the top surface layer, the average NSI of the thermal hydraulic conductivity is 3.6, and the average NSI of the isothermal hydraulic conductivity is 4.3. According to equation (21), this means that $K_{L T}$ and $K_{L h}$ with airflow are 3.6 and 4.3 times larger than those without airflow, respectively. This validates the direct reason assumed for the underestimation error and invalidates the indirect reason. The isothermal hydraulic conductivity in the simulation including airflow does be over that neglecting airflow, as the beginning of section 3.3 assumed. However, with the downward temperature gradient (daytime) in mind (no large difference in temperature gradient, as Figures 6a and $7 \mathrm{~b}$ show), the higher thermal hydraulic conductivity in the simulation including airflow can induce higher downward thermal fluxes than that neglecting airflow, which is the opposite of the assumed indirect reason for the underestimation error. This invalidates the indirect reason for the underestimation error. The underestimation error should be mainly attributed to the combined effect between the isothermal hydraulic conductivity and the soil matric potential gradient, as discussed at the beginning of section 3.3.

[43] Figure $6 \mathrm{~b}$ shows the diurnal variation of the soil matric potential gradient difference induced by neglecting
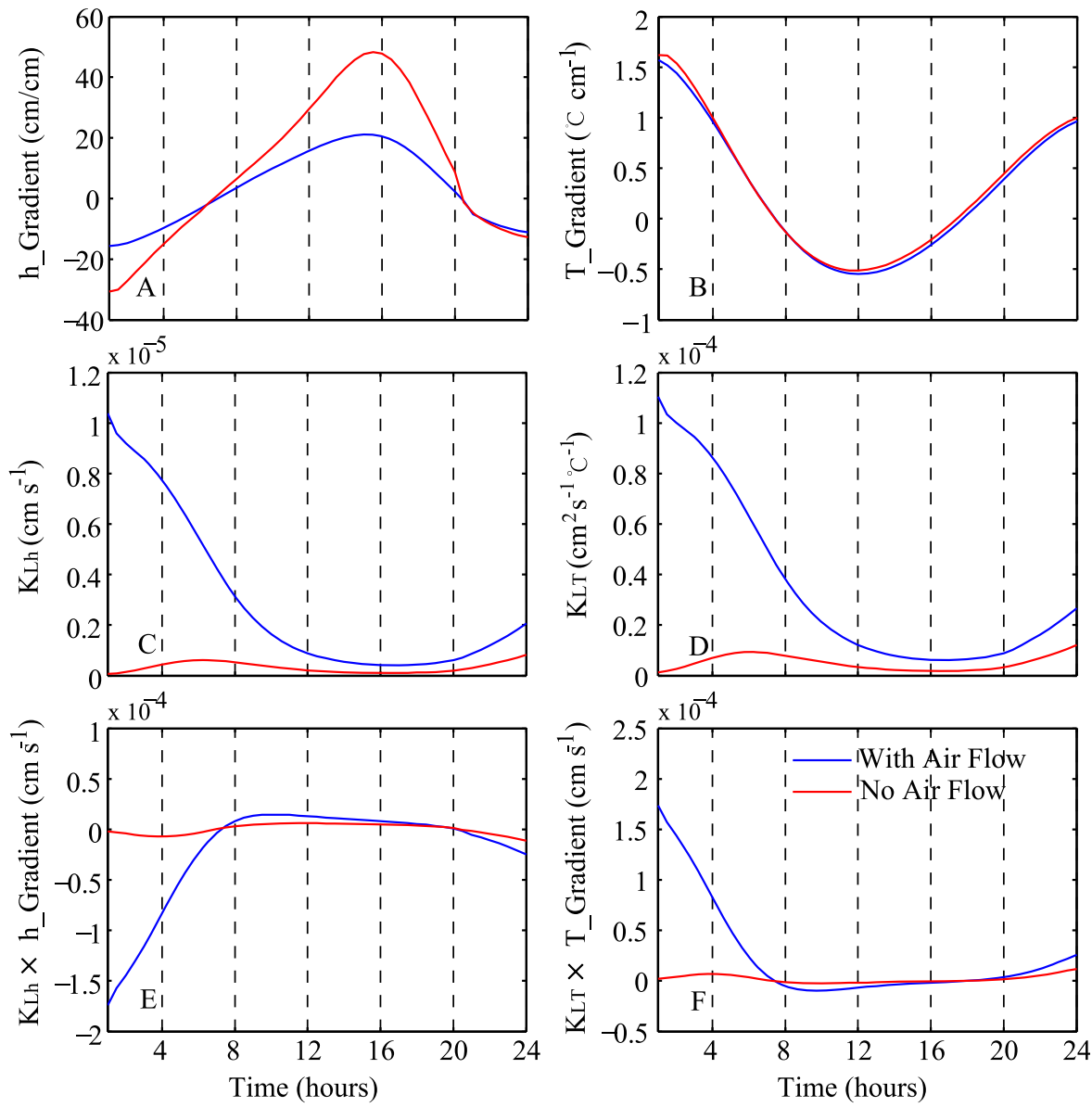

Figure 7. The comparison of gradients and conductivities in the top surface layer on the day right after rainfall for the high-permeability soil. 
airflow. With the above analysis in mind, only the second day is selected. In the top surface layer, the average NSI is 2.13, $\overline{\mathrm{NSI}}_{\max }$ is 7.8 , and $\overline{\mathrm{NSI}}_{\min }$ is -1.4 . This denotes that the average soil matric potential gradient in the surface layer without airflow is 2.13 times larger, on average, than that with airflow, which means that the isothermal hydraulic conductivity with airflow should be larger than that without airflow in order to have a higher evaporative flux on the surface, which is exactly the case, as Figure $7 \mathrm{c}$ and the NSI index of conductivity show.

[44] Figure 7 shows a comparison of gradients, conductivities, and the products of the two in the top surface layer on the second day of the selected period for the high-permeability soil. It is clear that the upward matric potential gradient without airflow is higher than that with airflow (Figure 7a); the downward temperature gradient is slightly higher when the airflow is considered (Figure $7 \mathrm{~b}$ ), and the isothermal and thermal hydraulic conductivities with airflow are much higher than those without airflow (Figures $7 \mathrm{c}$ and $7 \mathrm{~d}$ ). Then, the products of the gradients and conductivities produce the isothermal liquid flux and the thermal liquid flux (Figures 7e and 7f). After comparing Figure 7e to Figure $4 \mathrm{a}$, it is evident that only the isothermal liquid flux can contribute directly to the advective effect on evaporation.

\subsubsection{Comparison in the Low-Permeability Soil}

[45] Figure 8 shows that the variation pattern of the differences in driving forces and conductivities induced by neglecting airflow in the low-permeability soil is similar to that in the high-permeability soil. The average NSI of the soil temperature gradient difference is 0.18 throughout the profile for the selected period. For the day right after the rainfall event, the average NSI becomes 0.32 for the profile. When only the downward temperature gradient is considered, the average NSI for the profile is -0.11 in the day. If only the top surface layer $(0.25 \mathrm{~cm}$ thick $)$ is selected, the average NSI is -0.848 in the day. Compared to the highpermeability soil, the temperature gradient difference is much smaller in the low-permeability soil, especially for the top surface layer (Figure 8a). The downward temperature gradient with airflow remains higher than that without airflow (Figure 9b), which produces no change in the pattern of the thermal liquid fluxes (Figure 9f) compared to that in the high-permeability soil (Figure 7f).

[46] In the top surface layer, the thermal hydraulic conductivity without airflow (Figure 9d) remains almost unchanged compared to that with airflow. This is also true for the isothermal hydraulic conductivity (Figure 9c). The difference (between with and without airflow) in the thermal hydraulic conductivity in the low-permeability soil

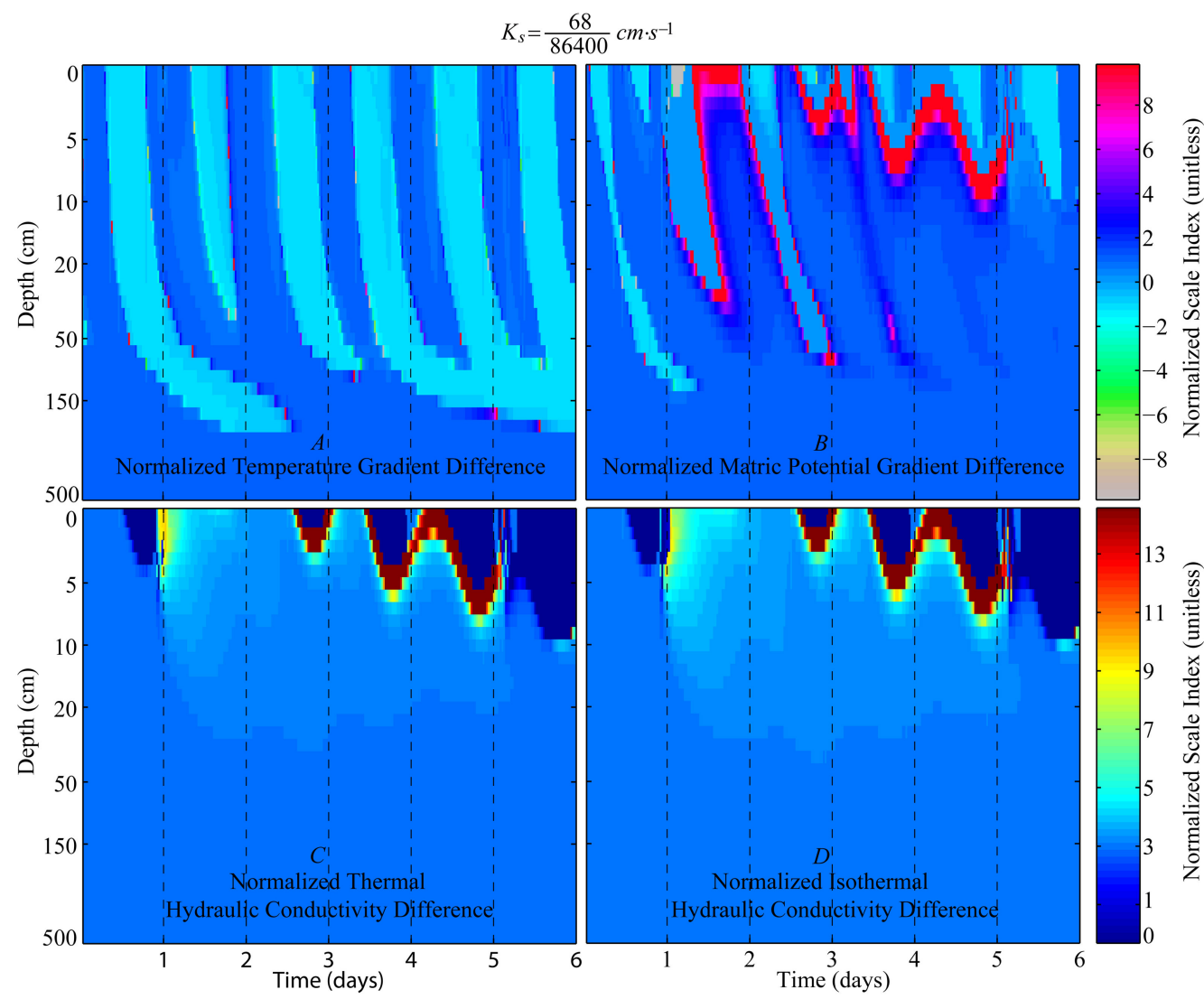

Figure 8. Spatial and temporal distributions of normalized scale index for (a) soil temperature gradient difference, (b) soil matric potential gradient difference, (c) thermal hydraulic conductivity difference, and (d) isothermal hydraulic conductivity difference induced by neglecting soil airflow in the lowpermeability soil. 

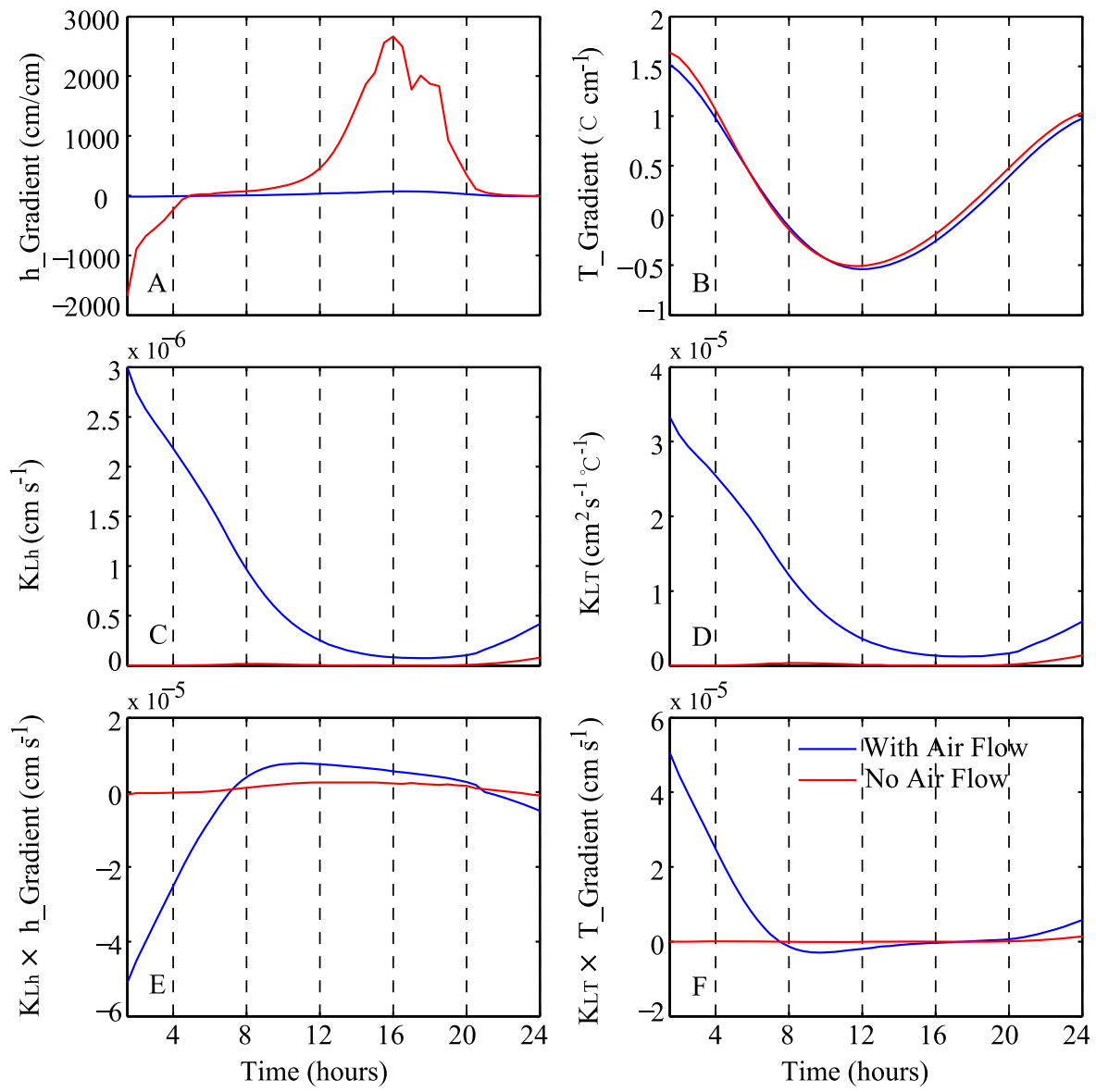

Figure 9. The comparison of gradients and conductivities in the top surface layer on the day right after rainfall for the low-permeability soil.

(Figure 8c, NSI $=38.8$ ) is about 10 times higher than that in the high-permeability soil (Figure $6 \mathrm{c}$, NSI $=3.6$ ). Likewise, the isothermal hydraulic conductivity difference in the low-permeability soil (Figure $8 \mathrm{~d}$, NSI $=57.2$ ) is also much higher than that in the high-permeability soil (Figure $6 \mathrm{~d}, \mathrm{NSI}=4.3$ ).

[47] Compared to the pattern in Figure 7e (the highpermeability soil), the pattern of the isothermal liquid flux in the low-permeability soil (Figure 9e) doesn't change, despite of that the soil matric potential gradient without airflow is much higher than that with airflow (Figures $8 b$ and $9 a$, NSI $=24.1$ ). This also indicates the dominant role the isothermal liquid flux plays in the advective effect on evaporation.

\section{Discussion and Conclusions}

[48] In order to evaluate the advective effect on evaporation, a two-phase heat and mass flow model was developed on the basis of a set of coupled moisture and heat equations. According to the independent variables (matric head, temperature, and air pressure), the isothermal, thermal, and advective fluxes were defined on the basis of the gradient of each variable. The model is calibrated by the field-measured soil temperature and soil moisture content. The comparison between simulation and measurement indicates that the parameters in soil hydraulic properties assumed to be vertically homogeneous are likely not correct. Further investigation should be made to quantify the heterogeneity of the sand in the field site.

[49] With the calibrated model, the advective effect on evaporation was investigated in both the high- and lowpermeability soils. Neglecting the soil airflow can cause an underestimation of evaporation by $8.85 \%$ in the lowpermeability soil and $6.4 \%$ in the high-permeability soil. The most noticeable underestimation error occurred in the day right after the rainfall event. In the day, the underestimation error is $33.3 \%$ in the high-permeability soil and $53.3 \%$ in the low-permeability soil. In the rest of the selected period, because of the drying of the shallow surface layer, the soil matric potential is extremely low and makes the hydraulic conductivity equal to zero, which subsequently leads to an insignificant advective effect on evaporation. The advective effect is much more evident in the low-permeability soil than in the high-permeability soil. The high permeability leads to high soil air velocity. However, the high air velocity means that the soil air pressure can equilibrate quickly with the atmospheric pressure, which will result in a small air pressure head gradient in the soil.

[50] The analysis of the gradient fields (Figure 5) in the simulation with airflow showed that the soil matric potential gradient should be the direct driving force for the underestimation error induced by neglecting airflow. 

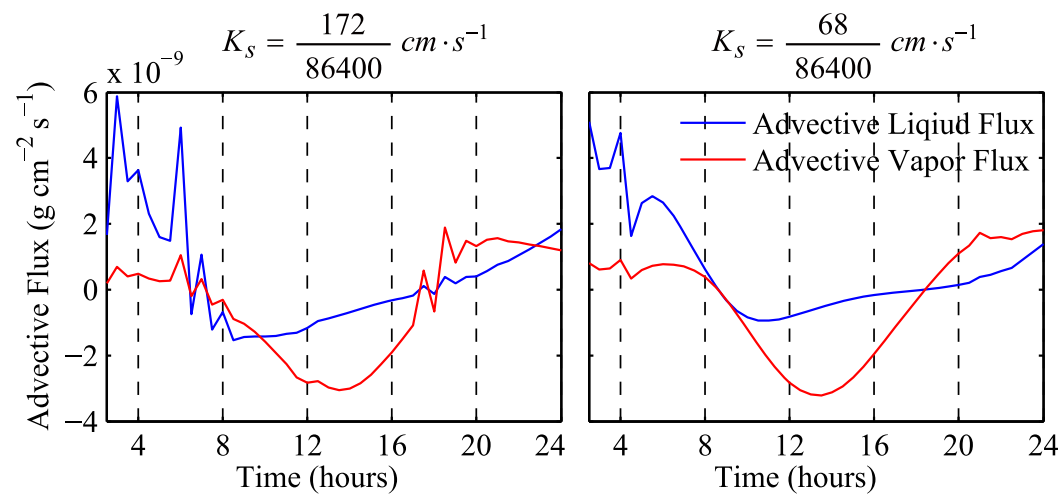

Figure 10. The advective liquid and vapor fluxes in the top surface layer on the day right after rainfall for the high- and low-permeability soils.

Considering the soil temperature gradient is downward during the day, it was thought to be the possible indirect driving force for the error. The downward thermal flux is possibly higher in the simulation neglecting airflow than that considering airflow, which suppresses the evaporative flux on the surface. After comparing the gradient fields and the conductivity fields (Figures 6 and 8), the indirect reason for the underestimation error was excluded. The underestimation error induced by neglecting airflow is mainly attributed to the isothermal liquid flux because of the upward soil matric potential gradient during the day. However, the soil matric potential gradient is still not the direct driving force for the underestimation error. The difference of the hydraulic conductivity induced by neglecting airflow is the key to explaining the error. When the airflow is neglected, the isothermal hydraulic conductivity is reduced tremendously. In the top surface layer, it is reduced 4.3 and 57.2 times in the high- and low-permeability soils, respectively. This is further supported by the fact that even when the soil matric potential gradient in the top surface layer increases by a large amount after neglecting airflow (it was increased 2.13 and 24.1 times in the high- and low-permeability soils, respectively), the upward isothermal liquid flux is still lower than that when considering airflow (Figures $7 \mathrm{e}$ and $9 \mathrm{e})$. This discussion also explains why the advective effect is more evident in the low-permeability soil.

[51] The sharp decrease of the isothermal hydraulic conductivity due to the lack of airflow can be explained by the absence of downward advective fluxes. During the daytime, the soil air pressure gradient is downward, which directs the advective liquid and vapor flux downward, as Figure 10 shows. Although the magnitude of the advective flux is at least 3 orders less than those of the thermal and isothermal liquid fluxes, the downward advective fluxes still can moisten the top surface layer and thus increase the hydraulic conductivity. When the airflow is neglected, the lack of downward advective fluxes in the top surface layer makes the hydraulic conductivity almost stable during the day, especially in the low-permeability soil (Figures 7c and 9c). The small spike in the fluctuation of the advective flux in the top surface layer is partially due to the strong variation of the soil matric potential gradient, which subsequently affects the soil air pressure gradient at the surface and is partially due to the atmospheric pressure variation and the unstable wind speed at the surface.
[52] From this discussion, the advective effect on evaporation is dominant in the low-permeability soil, while it is relatively insignificant in the high-permeability soil. The advective effect on evaporation is reflected by the underestimation error induced by neglecting airflow. It indicates that when the soil was very dry (e.g., desert sand) the enhanced vapor transfer induced by the air pressure gradient can increase the hydraulic conductivity tremendously and thus indirectly causes the high upward isothermal liquid flux. This fact denotes that the vapor transfer can be enhanced not only by the temperature gradient but also by the air pressure gradient. The simulation analysis was based on the field measurement in a desert, and more analysis should be conducted with a wider range of soil wetness, soil materials, weather conditions, and so on. Last but not least, the vapor transfer can be enhanced further when a solute in the soil water is considered [Webb and Ho, 1998]. Future studies should be conducted that include the solute effect on evaporation using a two-phase flow approach.

\section{Appendix A: Constitutive Equations}

\section{A1. Hydraulic Characteristics}

[53] The pore size distribution model of Mualem [1976] was used to predict the isothermal hydraulic conductivity $K_{L h}$ from the saturated hydraulic conductivity [van Genuchten, 1980]:

$$
K_{L h}=K_{s} K_{r h}=K_{s} S_{e}^{l}\left[1-\left(1-S_{e}^{1 / m}\right)^{m}\right]^{2},
$$

where $K_{s}\left(\mathrm{~m} \mathrm{~s}^{-1}\right)$ is the saturated hydraulic conductivity, $K_{r h}$ is the relative hydraulic conductivity, $S_{e}$ is the effective saturation (unitless; $\left.S_{e}=\left(\theta-\theta_{\text {res }}\right) /\left(\theta_{\text {sat }}-\theta_{\text {res }}\right)\right)$, $\theta_{\text {res }}$ is the residual water content, and $l$ and $m$ are empirical parameters. Of these parameters, $l=0.5$, and $m$ is a measure of the pore size distribution and can be expressed as $m=1-1 / n$, which could be determined by fitting van Genuchten's analytical model [van Genuchten, 1980],

$$
\theta(h)=\left\{\begin{array}{cc}
\theta_{\text {res }}+\frac{\theta_{\text {sat }}-\theta_{\text {res }}}{\left[1+|\alpha h|^{n}\right]^{m}}, & h<0, \\
\theta_{\text {sat }}, & h \geq 0,
\end{array}\right.
$$


where $\alpha\left(\mathrm{m}^{-1}\right)$ is the parameter characteristic of the particular soil material. Using the moisture content and matric potential measurement, the soil water retention curve parameters were determined by Zeng et al. [2009] as $\theta_{\text {sat }}=0.382, \theta_{\text {res }}=0.017, \alpha=0.00236$, and $n=3.6098$. According to Scanlon [2000], the intrinsic permeability of a media may be defined as

$$
k_{g}=\frac{K_{s} \mu_{w}}{\rho_{L} g},
$$

where $\mu_{w}\left(\mathrm{~kg} \mathrm{~m}^{-1} \mathrm{~s}^{-1}\right)$ is the dynamic viscosity of water.

\section{A2. Thermal Liquid Conductivity}

[54] Taking the temperature dependence of the matric pressure into consideration [Nassar and Horton, 1989; Nimmo and Miller, 1986; Noborio et al., 1996], the thermal hydraulic conductivity $K_{L T}$ is defined as

$$
K_{L T}=K_{L h}\left(h G_{w T} \frac{1}{\gamma_{0}} \frac{\mathrm{d} \gamma}{\mathrm{d} T}\right)
$$

where $G_{w T}$ is the gain factor (dimensionless), which assesses the temperature dependence of the surface tension of soil water, $\gamma\left(\mathrm{g} \mathrm{s}^{-2}\right)$ is the surface tension of soil water, and $\gamma_{0}\left(71.89 \mathrm{~g} \mathrm{~s}^{-2}\right)$ is the surface tension at $25^{\circ} \mathrm{C}$. The temperature dependence of $\gamma$ is given by [Saito et al., 2006]

$$
\gamma=75.6-0.1425 T-2.38 \times 10^{-4} T^{2},
$$

where $T\left({ }^{\circ} \mathrm{C}\right)$ is the temperature.

[55] According to Groenevelt and Kay [1974], the transport coefficient for adsorbed liquid flow due to the temperature gradient may be expressed as

$$
D_{T D}=\frac{H_{w} \varepsilon}{b f_{0} \mu_{w}(T+273.15)}\left(1.5548 \times 10^{-17}\right),
$$

where $H_{w}\left(\mathrm{~J} \mathrm{~m}^{-2}\right)$ is the integral heat of wetting, $b=4 \times$ $10^{-8} \mathrm{~m}, T\left({ }^{\circ} \mathrm{C}\right)$ is the temperature, and $f_{0}$ is the tortuosity factor, which may be expressed as [Millington and Quirk, 1961]

$$
f_{0}=\theta_{a}^{7 / 3} / \theta_{\mathrm{sat}}^{2}
$$

[56] The dynamic viscosity of water given by Fogel'son and Likhachev [2000] is

$$
\mu_{w}=\mu_{w 0} \exp \left[\mu_{1} / R(T+133.3)\right]
$$

where $\mu_{w 0}=2.4152 \times 10^{-5} \mathrm{~Pa} \mathrm{~s}, \mu_{1}=4.7428 \mathrm{~kJ} \mathrm{~mol}^{-1}$, $R=8.314472 \mathrm{~J} \mathrm{~mol}^{-1}{ }^{\circ} \mathrm{C}^{-1}$, and $T\left({ }^{\circ} \mathrm{C}\right)$ is the temperature.

\section{A3. Vapor Transport Coefficients}

[57] According to equation (10), there are three transport coefficients, which are identified as the isothermal vapor conductivity $D_{v h}$, the thermal vapor diffusion coefficient $D_{v T}$, and the advective vapor transfer coefficient $D_{v a}$. For the thermal vapor diffusion coefficient, the enhancement factor introduced by Philip and de Vries [1957] should be included as

$$
D_{v T}=\left(D_{e} \eta+D_{V g}\right) \frac{\partial \rho_{V}}{\partial T}
$$

where $\eta$ is the enhancement factor and is expressed as [Cass et al., 1984]

$$
\eta=9.5+3\left(\theta / \theta_{\text {sat }}\right)-8.5 \exp \left\{-\left[\left(1+2.6 / \sqrt{f_{c}}\right) \theta / \theta_{\text {sat }}\right]^{4}\right\}
$$

where $f_{c}$ is the mass fraction of clay in the sand (0.02). Note that in $D_{v h}$ and $D_{v T}$, there is a longitudinal dispersion coefficient $D_{v g}$, which is estimated by Bear [1972] as

$$
D_{v g}=\alpha_{L i}\left|q_{i}\right|_{(i=\text { gas,liquid })},
$$

where $q_{i}$ is the pore fluid flux in phase $i$ and $\alpha_{L i}(\mathrm{~m})$, the longitudinal dispersivity in phase $i$, has been evaluated by various authors for different levels of soil saturation. Laboratory studies have shown that $\alpha_{L i}$ increases when the soil volumetric water content decreases. In this work, as in the work by Grifoll et al. [2005], a correlation made from simulation results of Sahimi et al. [1986] and experimental data obtained by Haga et al. [1999] was used:

$$
\alpha_{L i}=\alpha_{L i \_s a t}\left[13.6-16\left(\theta_{a} / \varepsilon\right)+3.4\left(\theta_{a} / \varepsilon\right)^{5}\right] .
$$

[58] As Grifoll et al. [2005] pointed out, because of the lack of dispersivity values, the saturation dispersivity $\alpha_{L i \_s a t}$ used in (A12) was taken to be $0.078 \mathrm{~m}$, as reported in the field experiments of Biggar and Nielsen [1976] and as shown to be a reasonable value in previous modeling studies [Cohen and Ryan, 1989].

\section{Appendix B : Finite Element Method}

[59] To describe the spatial discretization and time stepping of the governing equations, an example of the derivation is presented for one case only. In particular, the moisture equation is used. For the dry air equation and energy equation, the procedure is similar. The standard piecewise linear basis functions for approximating the prime variables are expressed as

$$
\begin{aligned}
& \hat{h}(z, t)=h_{1} \phi_{1}+h_{2} \phi_{2}=\sum_{j=1}^{2} h_{j}(t) \phi_{j}(z), \\
& \hat{T}(z, t)=T_{1} \phi_{1}+T_{2} \phi_{2}=\sum_{j=1}^{2} T_{j}(t) \phi_{j}(z), \\
& \hat{P}_{g}(z, t)=P_{g 1} \phi_{1}+P_{g 2} \phi_{2}=\sum_{j=1}^{2} P_{g_{j}}(t) \phi_{j}(z),
\end{aligned}
$$

where $j$ is the node index and $\phi_{j}(z)$ is the usual shape function defined element by element. If the approximations given by equation (B1) are substituted into equations (10), (13), and (15), residuals are obtained for each governing differential equation, which is then minimized using Galerkin's method. Introducing new notation for the coefficients 
in the moisture mass conservation equation, we have, from equation (10),

$$
\begin{aligned}
& M_{\text {moisture }}(h, T)=c_{1} \frac{\partial h}{\partial t}+c_{2} \frac{\partial T}{\partial t}-\frac{\partial}{\partial z}\left(c_{3} \frac{\partial h}{\partial z}+c_{4} \frac{\partial T}{\partial z}+c_{5} \frac{\partial P_{g}}{\partial z}+c_{6}\right) \\
& -c_{7} \frac{\partial h}{\partial z}-c_{8} \frac{\partial T}{\partial z},
\end{aligned}
$$

where $c_{1}$ through $c_{8}$ are defined implicitly by equations (10) and (B2). Following Galerkin's method of weighted residuals for each element, we require that the residuals obtained by substituting $\hat{h}, \hat{T}$, and $\hat{P}_{g}$ into equation (B2) be orthogonal to the set of trial functions.

$$
\begin{gathered}
\int_{Z}\left[c_{1} \frac{\partial \hat{h}}{\partial t}+c_{2} \frac{\partial \hat{T}}{\partial t}-\frac{\partial}{\partial z}\left(c_{3} \frac{\partial \hat{h}}{\partial z}+c_{4} \frac{\partial \hat{T}}{\partial z}+c_{5} \frac{\partial \hat{P}_{g}}{\partial z}+c_{6}\right)\right. \\
\left.-c_{7} \frac{\partial \hat{h}}{\partial z}-c_{8} \frac{\partial \hat{T}}{\partial z}\right] \phi_{i} \mathrm{~d} z=0, i=1,2,
\end{gathered}
$$

where $Z$ is the solution domain. We apply integration by part to the third, fourth, and fifth terms, which may be recognized as the flux divergence.

$$
\begin{aligned}
& \int_{Z}\left(c_{1} \frac{\partial \hat{h}}{\partial t}+c_{2} \frac{\partial \hat{T}}{\partial t}\right) \phi_{i} \mathrm{~d} z+\int_{Z}\left(c_{3} \frac{\partial \hat{h}}{\partial z}+c_{4} \frac{\partial \hat{T}}{\partial z}+c_{5} \frac{\partial \hat{P}_{g}}{\partial z}+c_{6}\right) \phi_{i}^{\prime} \mathrm{d} z \\
& +\int_{Z} c_{7} \hat{h} \phi_{i}^{\prime} \mathrm{d} z+\int_{Z} c_{8} \hat{T} \phi_{i}^{\prime} \mathrm{d} z \\
& =\left\{\left[\left(c_{3} \frac{\partial \hat{h}}{\partial z}+c_{4} \frac{\partial \hat{T}}{\partial z}+c_{5} \frac{\partial \hat{P}_{g}}{\partial z}+c_{6}\right)+c_{7} \hat{h}+c_{8} \hat{T}\right] \phi_{i}\right\}_{z_{1}}^{z_{2}} \\
& =\left[-Q_{m} \phi_{i}\right]_{I_{1}}^{z_{2}}, i=1,2
\end{aligned}
$$

where $z_{1}$ and $z_{2}$ are two points in one element and the subscripts are according to the local numbering system. According to the definition of $c_{3}, c_{4}, c_{5}, c_{6}, c_{7}$, and $c_{8}$, we set $Q_{m}$ implicitly as the sum of liquid and vapor mass fluxes. Now, substituting from equation (B1) into equation (B4) yields

$$
\begin{aligned}
& \sum_{j=1}^{2} h_{j}^{\prime} \int c_{1} \phi_{j} \phi_{i} \mathrm{~d} z+\sum_{j=1}^{2} T_{j}^{\prime} \int c_{2} \phi_{j} \phi_{i} \mathrm{~d} z+\sum_{j=1}^{2} h_{j} \int c_{3} \phi_{j}^{\prime} \phi_{i}^{\prime} \mathrm{d} z \\
& +\sum_{j=1}^{2} T_{j} \int c_{4} \phi_{j}^{\prime} \phi_{i}^{\prime} \mathrm{d} z+\sum_{j=1}^{2} P_{g j} \int c_{5} \phi_{j}^{\prime} \phi_{i}^{\prime} \mathrm{d} z+\int c_{6} \phi_{i}^{\prime} \mathrm{d} z \\
& +\sum_{j=1}^{2} h_{j} \int c_{7} \phi_{j} \phi_{i}^{\prime} \mathrm{d} z+\sum_{j=1}^{2} T_{j} \int c_{8} \phi_{j} \phi_{i}^{\prime} \mathrm{d} z \\
& =\left[-Q_{m} \phi_{i}\right]_{z_{1}}^{z_{2}}, i=1,2 .
\end{aligned}
$$

[60] Considering the dependence of $c_{1}$ through $c_{8}$ on state variables, the linear assumption of the parameters inside an element is made with the same form as in equation (B1). In matrix form, equation (B5) becomes

$$
A \dot{h}+B \dot{T}+C h+D T+E P_{g}+F=\left.Q_{m}\right|_{\Gamma},
$$

where $A, B, C, D, E$, and $F$ are defined implicitly by equations (B5) and (B6), the subscript $\Gamma$ denotes the boundary of the solution domain, by which the specific boundary conditions enter into the equations associated with the two end nodes, and $\dot{h}$ and $\dot{T}$ denote the time derivatives of the matric potential and temperature, respectively. A fully implicit backward difference scheme is used to accomplish the temporal solution of the governing differential equations, which means that all terms other than the time derivative are evaluated at the end of the time step, and it yields

$$
\begin{aligned}
& \left(\frac{1}{\Delta t} A^{k}+C^{k}\right) h^{k}+\left(\frac{1}{\Delta t} B^{k}+D^{k}\right) T^{k}=\frac{1}{\Delta t} A^{k} h^{k-1} \\
& +\frac{1}{\Delta t} B^{k} T^{k-1}-E P_{g}^{k}-F+\left.Q_{m}\right|_{\Gamma},
\end{aligned}
$$

where $k$ is a time index and $\Delta t$ is the length of the time step. The coefficient matrices in equation (B7) are to be evaluated at the new time level with an iterative scheme, which updates the coefficient matrices each iteration until desired convergence criteria are achieved.

\section{Notation}

$\theta \quad$ volumetric water content $\left(\mathrm{m}^{3} \mathrm{~m}^{-3}\right)$.

$\theta_{a} \quad$ volumetric air content $\left(\mathrm{m}^{3} \mathrm{~m}^{-3}\right)$.

$\theta_{s} \quad$ volumetric content of solid $\left(\mathrm{m}^{3} \mathrm{~m}^{-3}\right)$.

$\theta_{\text {sat }} \quad$ saturated water content $\left(\mathrm{m}^{3} \mathrm{~m}^{-3}\right)$.

$\theta_{\text {res }} \quad$ residual water content $\left(\mathrm{m}^{3} \mathrm{~m}^{-3}\right)$.

$\varepsilon$ porosity (dimensionless).

$S_{e} \quad$ effective saturation (dimensionless).

$S_{r} \quad$ saturation (dimensionless).

$S_{a} \quad$ air saturation (dimensionless).

$\rho_{L} \quad$ density of liquid water $\left(\mathrm{kg} \mathrm{m}^{-3}\right)$.

$\rho_{V}$ density of water vapor $\left(\mathrm{kg} \mathrm{m}^{-3}\right)$.

$\rho_{v s} \quad$ vapor density in the top soil layer $\left(\mathrm{kg} \mathrm{m}^{-3}\right)$.

$\rho_{v a} \quad$ vapor density in air at certain height $\left(\mathrm{kg} \mathrm{m}^{-3}\right)$.

$\rho_{d a} \quad$ density of dry air $\left(\mathrm{kg} \mathrm{m}^{-3}\right)$.

$\rho_{S} \quad$ density of solid $\left(\mathrm{kg} \mathrm{m}^{-3}\right)$.

$\rho_{S V}$ density of saturated water vapor $\left(\mathrm{kg} \mathrm{m}^{-3}\right)$.

$q_{m}$ total soil moisture flux $\left(\mathrm{kg} \mathrm{m}^{-2} \mathrm{~s}^{-1}\right)$.

$q_{L} \quad$ liquid flux $\left(\mathrm{kg} \mathrm{m}^{-2} \mathrm{~s}^{-1}\right)$.

$q_{V} \quad$ vapor flux $\left(\mathrm{kg} \mathrm{m}^{-2} \mathrm{~s}^{-1}\right)$.

$q_{a} \quad$ dry air flux $\left(\mathrm{kg} \mathrm{m}^{-2} \mathrm{~s}^{-1}\right)$

$E$ Evaporation Rate $\left(\mathrm{kg} \mathrm{m}^{-2} \mathrm{~s}^{-1}\right)$

$r_{a}$ aerodynamic resistance for evaporation $\left(\mathrm{m}^{-1} \mathrm{~s}\right)$.

$r_{s}$ surface resistance for evaporation $\left(\mathrm{m}^{-1} \mathrm{~s}\right)$.

$P$ precipitation rate $\left(\mathrm{m} \mathrm{s}^{-1}\right)$.

$q_{L h}$ isothermal liquid flux $\left(\mathrm{kg} \mathrm{m}^{-2} \mathrm{~s}^{-1}\right)$.

$q_{L T} \quad$ thermal liquid flux $\left(\mathrm{kg} \mathrm{m}^{-2} \mathrm{~s}^{-1}\right)$.

$q_{L a} \quad$ advective liquid flux $\left(\mathrm{kg} \mathrm{m}^{-2} \mathrm{~s}^{-1}\right)$.

$q_{v h}$ isothermal vapor flux $\left(\mathrm{kg} \mathrm{m}^{-2} \mathrm{~s}^{-1}\right)$.

$q_{v T}$ thermal vapor flux $\left(\mathrm{kg} \mathrm{m}^{-2} \mathrm{~s}^{-1}\right)$.

$q_{v a}$ advective vapor flux $\left(\mathrm{kg} \mathrm{m}^{-2} \mathrm{~s}^{-1}\right)$.

$q_{a h}$ isothermal air flux $\left(\mathrm{kg} \mathrm{m}^{-2} \mathrm{~s}^{-1}\right)$.

$q_{a T}$ thermal air flux $\left(\mathrm{kg} \mathrm{m}^{-2} \mathrm{~s}^{-1}\right)$.

$q_{a a}$ advective dry air flux $\left(\mathrm{kg} \mathrm{m}^{-2} \mathrm{~s}^{-1}\right)$.

$K_{a h}$ isothermal air transfer coefficient $\left(\mathrm{kg} \mathrm{m}^{-2} \mathrm{~s}^{-1}\right)$. 
$K_{a T}$ thermal air transfer coefficient $\left(\mathrm{kg} \mathrm{m}^{-1} \mathrm{~s}^{-1} \mathrm{C}^{-1}\right)$.

$K_{a a}$ advective air transfer coefficient (s).

$D_{v h}$ isothermal vapor transfer coefficient $\left(\mathrm{kg} \mathrm{m}^{-2} \mathrm{~s}^{-1}\right)$.

$D_{v T}$ thermal vapor transfer coefficient $\left(\mathrm{kg} \mathrm{m}^{-1} \mathrm{~s}^{-1} \mathrm{C}^{-1}\right)$.

$D_{v a}$ advective vapor transfer coefficient (s).

$K_{s} \quad$ saturated hydraulic conductivity $\left(\mathrm{m} \mathrm{s}^{-1}\right)$.

$K_{r h}$ relative hydraulic conductivity (dimensionless).

$k_{g}$ intrinsic air permeability $\left(\mathrm{m}^{2}\right)$.

$K_{L h} \quad$ isothermal hydraulic conductivity $\left(\mathrm{m} \mathrm{s}^{-1}\right)$.

$K_{L T} \quad$ thermal hydraulic conductivity $\left(\mathrm{m}^{2} \mathrm{~s}^{-1}{ }^{\circ} \mathrm{C}^{-1}\right)$.

$D_{T D}$ transport coefficient for adsorbed liquid flow due to temperature gradient $\left(\mathrm{m}^{2} \mathrm{~s}^{-1}{ }^{\circ} \mathrm{C}^{-1}\right)$.

$D_{e}$ molecular diffusivity of water vapor $\left(\mathrm{m}^{2} \mathrm{~s}^{-1}\right)$.

$D_{a}$ diffusivity of water vapor in air $\left(\mathrm{m}^{2} \mathrm{~s}^{-1}\right)$.

$D_{V g}$ longitudinal dispersion coefficient $\left(\mathrm{m}^{2} \mathrm{~s}^{-1}\right)$.

$\gamma_{w}$ specific weight of water $\left(\mathrm{kg} \mathrm{m}^{-2} \mathrm{~s}^{-2}\right)$.

$\mu_{a}$ air viscosity $\left(\mathrm{kg} \mathrm{m}^{-1} \mathrm{~s}^{-1}\right)$.

$\mu_{w} \quad$ dynamic viscosity of water $\left(\mathrm{kg} \mathrm{m}^{-1} \mathrm{~s}^{-1}\right)$.

$P_{g} \quad$ pore air pressure $(\mathrm{Pa})$.

$g$ gravitational acceleration $\left(\mathrm{m} \mathrm{s}^{-2}\right)$.

$h$ matric potential head $(\mathrm{m})$.

$z \quad$ vertical space coordinate (positive Upward) (m).

$T$ temperature $\left({ }^{\circ} \mathrm{C}\right)$.

$T_{r}$ reference temperature $\left({ }^{\circ} \mathrm{C}\right)$.

$H_{c} \quad$ Henry's constant (dimensionless).

$H_{r}$ relative humidity (dimensionless).

$G_{w T}$ gain factor for thermal hydraulic conductivity (dimensionless).

$R_{v} \quad$ specific gas constant for vapor $\left(\mathrm{J} \mathrm{Kg}^{-1} \mathrm{~K}^{-1}\right)$.

$R_{d a} \quad$ specific gas constant for air $\left(\mathrm{J} \mathrm{Kg}^{-1} \mathrm{~K}^{-1}\right)$.

$c_{s} \quad$ specific heat of solid $\left(\mathrm{J} \mathrm{Kg}^{-1}{ }^{\circ} \mathrm{C}^{-1}\right)$.

$c_{L} \quad$ specific heat of liquid $\left(\mathrm{J} \mathrm{Kg}^{-1}{ }^{\circ} \mathrm{C}^{-1}\right)$.

$c_{a} \quad$ specific heat of air $\left(\mathrm{J} \mathrm{Kg}^{-1}{ }^{\circ} \mathrm{C}^{-1}\right)$.

$c_{v}$ specific heat of vapor $\left(\mathrm{J} \mathrm{Kg}^{-1}{ }^{\circ} \mathrm{C}^{-1}\right)$.

$L_{0}$ latent heat of vaporization of water at reference temperature $\left(\mathrm{J} \mathrm{Kg}^{-1}\right)$.

$L \quad$ latent heat of vaporization $\left(\mathrm{J} \mathrm{Kg}^{-1}\right)$.

$W$ differential heat of wetting $\left(\mathrm{J} \mathrm{Kg}^{-1}\right)$. $\begin{array}{ll}W & \text { integral heat of wetting, equal to } \rho_{L} W \frac{\partial \theta}{\partial t} / \\ & \left(S_{\text {area }} \cdot \rho_{\text {bulk }}\right)\left(\mathrm{J} \mathrm{m}^{-2}\right) .\end{array}$

$S_{\text {area }} \quad$ surface area $\left(\mathrm{m}^{-1}\right)$.

$\rho_{\text {bulk }}$ bulk density $\left(\mathrm{kg} \mathrm{m}^{-3}\right)$.

$\lambda_{\text {eff }}$ effective thermal conductivity $\left(\mathrm{W} \mathrm{m}^{-1}{ }^{\circ} \mathrm{C}^{-1}\right)$. surface tension of water $\left(\mathrm{g} \mathrm{s}^{-2}\right)$.

thickness of liquid film (m).

$f_{0} \quad$ tortuosity factor (dimensionless).

$b_{1,2,3}$ empirical regression parameters for effective thermal conductivity (dimensionless).

[61] Acknowledgments. The research projects on which this paper is based were funded by The ESA-MOST Dragon Programme and by the European Commission (call FP7-ENV-2007-1, grant 212,921) as part of the CEOP-AEGIS project (http://www.ceop-aegis.org/) coordinated by the Université Louis Pasteur (and supported by the Fundamental Research Funds for the Central Universities.) We thank the anonymous referees very much for their helpful and constructive comments and suggestions for improving the manuscript.

\section{References}

Bear, J. (1972), Dynamics of Fluid in Porous Media, Dover, New York. Biggar, J. W., and D. R. Nielsen (1976), Spatial variability of the leaching characteristics of a field soil, Water Resour. Res., 1(1), 78-84, doi:10.1029/WR $012 \mathrm{i} 001 \mathrm{p} 00078$.
Bittelli, M., F. Ventura, G. S. Campbell, R. L. Snyder, F. Gallegati, and P. R. Pisa (2008), Coupling of heat, water vapor, and liquid water fluxes to compute evaporation in bare soils, J. Hydrol., 362(3-4), 191-205.

Cahill, A. T., and M. B. Parlange (1998), On water vapor transport in field soils, Water Resour. Res., 34(4), 731-739, doi:10.1029/97WR03756.

Camillo, P. J., and R. J. Gurney (1986), Resistance parameter for bare-soil evaporation models, Soil Sci., 141(2).

Campbell, G. S. (1985), Soil Physics With BASIC: Transport Models for Soil-Plant Systems, Elsevier, New York.

Cass, A., G. S. Campbell, and T. L. Jones (1984), Enhancement of thermal water vapor diffusion in soil, Soil Sci. Soc. Am. J., 48, 25-32.

Cohen, Y., and P. A. Ryan (1989), Chemical transport in the top soil zone. The role of moisture and temperature gradients, J. Hazard. Mater., 22(3), 283-304.

de Vries, D. A. (1958), Simultaneous transfer of heat and moisture in porous media, Eos Trans. AGU, 39(5), 909-916.

Fogel'son, R. L., and E. R. Likhachev (2000), Temperature dependence of diffusion coefficient, Phys. Met. Metallogr., 90(1), 58-61.

Fredlund, D. G., and H. Rahardjo (1993), Soil Mechanics for Unsaturated Soils, John Wiley, New York.

Gates, J. B., W. M. Edmunds, J. Z. Ma, and B. R. Scanlon (2008), Estimating groundwater recharge in a cold desert environment in northern China using chloride, Hydrogeol. J., 16(5), 893-910.

Gray, W. G., and S. M. Hassanizadeh (1991), Unsaturated flow theory including interfacial phenomena, Water Resour. Res., 27(8), 1855-1863, doi:10.1029/91WR01260.

Grifoll, J., J. M. Gast, and Y. Cohen (2005), Non-isothermal soil water transport and evaporation, Adv. Water Resour., 28, 1254-1266.

Groenevelt, P. H., and B. D. Kay (1974), On the interaction of water and heat transport in frozen and unfrozen soils: II. The liquid phase, Soil Sci. Soc. Am. Proc., 38, 400-404.

Haga, D., Y. Niibori, and T. Chida (1999), Hydrodynamic dispersion and mass transfer in unsaturated flow, Water Resour. Res., 35(4), 1065-1077, doi:10.1029/1998WR900111.

Hillel, D. (2004), Introduction to Environmental Soil Physics, Elsevier, Amsterdam.

Kobayashi, T., W. J. He, and H. Nagai (1998), Mechanisms of evaporation from soil with a dry surface, Hydrol. Processes, 12(13-14), 2185-2191.

Kowalski, S. J. (2008), R\&D in thermo-hydro-mechanical aspect of drying, Drying Technol., 26(3), 258-259.

Millington, R. J., and J. P. Quirk (1961), Permeability of porous solids, Trans. Faraday Soc., 57, 1200-1207.

Milly, P. C. D. (1982), Moisture and heat transport in hysteretic, inhomogeneous porous media: A matric head-based formulation and a numerical model, Water Resour. Res., 18(3), 489-498, doi:10.1029/WR018i 003 p00489.

Milly, P. C. D. (1984a), A linear analysis of thermal effects on evaporation from soil, Water Resour. Res., 20(8), 1075-1085, doi:10.1029/WR020i 008 p01075.

Milly, P. C. D. (1984b), A simulation analysis of thermal effects on evaporati on from soil, Water Resour. Res., 20(8), 1087-1098, doi:10.1029/WR020i 008 p01087.

Milly, P. C. D., and P. S. Eagleson (1980), The coupled transport of water and heat in a vertical soil column under atmospheric excitation, report, Ralph M. Parsons Lab. for Water Resour. and Hydrodyn, Dep. of Civ. Eng., Mass. Inst. of Technol., Cambridge.

Mualem, Y. (1976), A new model for predicting the hydraulic conductivity of unsaturated porous media, Water Resour. Res., 12(3), 513-522, doi:10.1029/WR012i003p00513.

Nassar, I. N., and R. Horton (1989), Water transport in unsaturated nonisothermal salty soil. II: Theoretical development, Soil Sci. Soc. Am. J., 53, $1330-1337$.

Nimmo, J. R., and E. E. Miller (1986), The temperature dependence of isothermal moisture vs. potential characteristics of soils, Soil Sci. Soc. Am. $J ., 50,1105-1113$.

Noborio, K., K. J. McInnes, and J. L. Heilman (1996), Two-dimensional model for water, heat, and solute transport in furrow-irrigated soil: II. Field evaluation, Soil Sci. Soc. Am. J., 60, 1010-1021.

Olivella, S., and A. Gens (2000), Vapour transport in low permeability unsaturated soils with capillary effects, Transp. Porous Media, 40(2), $219-241$.

Parlange, M. B., A. T. Cahill, D. R. Nielsen, J. W. Hopmans, and O. Wendroth (1998), Review of heat and water movement in field soils, Soil Tillage Res., 47(5), 10. 
Philip, J. R., and V. D. de Vries (1957), Moisture movement in porous materials under temperature gradient, Eos Trans. AGU, 38(2), 222-232.

Prat, M. (2002), Recent advances in pore-scale models for drying of porous media, Chem. Eng. J., 86(1-2), 153-164.

Pruess, K. (2004), The TOUGH codes-A family of simulation tools for multiphase flow and transport processes in permeable media, Vadose Zone J., 3(3), 738-746.

Prunty, L. (2009), Thermomechanical theory of capillary soil water, Soil Sci. Soc. Am. J., 73, 494-500.

Rose, C. W. (1968a), Water transport in soil with a daily temperature wave. I. Theory and experiment, Aust. J. Soil Res., 6, 31-44.

Rose, C. W. (1968b), Water transport in soil with a daily temperature wave. II Analysis, Aust. J. Soil Res., 6, 45-57.

Sahimi, M., A. A. Heiba, H. T. Davis, and L. E. Scriven (1986), Dispersion in flow through porous media. II. Two-phase flow, Chem. Eng. Sci., 41(8), 2123-2136.

Saito, H., J. Simunek, and B. P. Mohanty (2006), Numerical analysis of coupled water, vapor, and heat transport in the vadose zone, Vadose Zone $J ., 5(2), 784-800$.

Sakai, M., N. Toride, and J. Simunek (2009), Water and vapor movement with condensation and evaporation in a sandy column, Soil Sci. Soc. Am. J., 73, 707-717.

Saxton, K. E., and W. J. Rawls (2006), Soil water characteristic estimates by texture and organic matter for hydrologic solutions, Soil Sci. Soc. Am. J., 70, 1569-1578.

Scanlon, B. R. (2000), Soil gas movement in unsaturated systems, in Handbook of Soil Science, edited by M. E. Sumner, CRC Press, Boca Raton, Fla.

Schrefler, B. A. (2004), Multiphase flow in deforming porous material, Int. J. Numer. Methods Eng., 60(1), 27-50.

Shokri, N., P. Lehmann, and D. Or (2009), Critical evaluation of enhancement factors for vapor transport through unsaturated porous media, Water Resour. Res., 45, W10433, doi:10.1029/2009WR007769.

Thomas, H. R., and M. R. Sansom (1995), Fully coupled analysis of heat, moisture, and air transfer in unsaturated soil, J. Eng. Mech., 121(3), $392-405$.

Thomas, H. R., Y. He, and C. Onofrei (1998), An examination of the validation of a model of the hydro/thermo/mechanical behaviour of engineered clay barriers, Int. J. Numer. Anal. Methods Geomech., 22(1), 49-71.
Tillman, F. D., and J. A. Smith (2005), Site characteristics controlling airflow in the shallow unsaturated zone in response to atmospheric pressure changes, Environ. Eng. Sci., 22(1), 25-37.

van de Griend, A. A., and M. Owe (1994), Bare soil surface resistance to evaporation by vapor diffusion under semiarid conditions, Water Resour. Res., 30(2), 181-188, doi:10.1029/93WR02747.

van Genuchten, M. T. (1980), A closed-form equation for predicting the hydraulic conductivity of unsaturated soils, Soil Sci. Soc. Am. J., 44, 892-898. van Genuchten, M. T., F. J. Leij, and S. R. Yates (1991), The RETC code for quantifying the hydraulic functions of unsaturated soils, Rep. EPA/ 600/2-91/065, U.S. Environ. Prot. Agency, Washington, D. C.

Vereecken, H., J. Huisman, H. Bogena, J. Vanderborght, J. Vrugt, and J. Hopmans (2008), On the value of soil moisture measurements in vadose zone hydrology: A review, Water Resour. Res., 44, W00D06, doi:10.1029/2008WR006829.

Webb, S. W., and C. K. Ho (1998), Review of enhanced vapor diffusion in porous media, SAND-98-1819C; CONF-980559.

Yiotis, A. G., A. G. Boudouvis, A. K. Stubos, I. N. Tsimpanogiannis, and Y. C. Yortsos (2004), Effect of liquid films on the drying of porous media, AiCHE J., 50(11), 2721-2737.

Yiotis, A. G., A. K. Stubos, A. G. Boudouvis, I. N. Tsimpanogiannis, and Y. C. Yortsos (2005), Pore-network modeling of isothermal drying in porous media, Transp. Porous Media, 58(1-2), 63-86.

Zeng, Y., Z. Su, L. Wan, Z. Yang, T. Zhang, H. Tian, X. Shi, X. Wang, and W. Cao (2009), Diurnal pattern of the drying front in desert and its application for determining the effective infiltration, Hydrol. Earth Syst. Sci., 13(6), 703-714.

Z. Su, Faculty of Geo-Information Science and Earth Observation, University of Twente, PO Box 217, NL-7500 AE Enschede, Netherlands. (b_su@itc.nl)

L. Wan and Y. Zeng, School of Water Resources and Environment, China University of Geosciences, Beijing 100083, China. (wanli@cugb. edu.cn; yijianzeng@gmail.com)

J. Wen, Key Laboratory of Land Surface Process and Climate Change in Cold and Arid Region, Cold and Arid Regions Environmental and Engineering Research Institute, Chinese Academy of Sciences, 320 Donggang West Road, Lanzhou 730000, China. (jwen@1zb.ac.cn) 